\title{
Regulation of translation initiation by FRAP/mTOR
}

\author{
Anne-Claude Gingras, ${ }^{1}$ Brian Raught, ${ }^{1}$ and Nahum Sonenberg ${ }^{2}$ \\ Department of Biochemistry and McGill Cancer Centre, McGill University, Montréal, Québec H3G 1Y6, Canada
}

\section{Translational control}

Regulation of protein synthesis in eukaryotes plays a critical role in development, differentiation, cell cycle progression, cell growth, and apoptosis (Mathews et al. 2000). Translational control allows for a more rapid response than transcriptional modulation because no mRNA synthesis, processing, or transport is required, and can be used to coordinate gene expression in systems that lack transcriptional regulation, such as reticulocytes or platelets (Weyrich et al. 1998; Mathews et al. 2000). Translational control plays a particularly important role in early developmental processes, when localized translation is utilized to establish polarity (Wickens et al. 2000), and localized translation in neurons may be critical for learning and memory (e.g., Casadio et al. 1999).

Following transcription, processing, and nucleocytoplasmic export, mRNAs are competent for translation. However, two transcripts present in identical quantities may be translated at very different rates. This phenomenon is caused, in part, by the fact that the ribosome does not bind to mRNA directly, but must be recruited to mRNA by the concerted action of a large number of eukaryotic translation initiation factors (eIFs). This recruitment step, also referred to as the initiation phase, is a complex process that culminates in the positioning of a charged ribosome (that is, an 80S ribosome loaded with an initiator tRNA in its $\mathrm{P}$ site) at an initiation codon (for review, see Hershey and Merrick 2000). As discussed further below, the recruitment process is rate-limiting for translation in many cases, and is subject to exquisite regulation.

The structure $\mathrm{m}^{7} \mathrm{GpppN}$ (or the cap, where $\mathrm{m}$ is a methyl group and $\mathrm{N}$ any nucleotide) is present at the 5' end of all nuclear transcribed mRNAs, and plays an important role in the initiation process. The cap is recognized by the initiation factor eIF4E. eIF4E, via an interaction with a large scaffolding protein termed eIF4G, directs the translational machinery to the $5^{\prime}$ end of the

\footnotetext{
${ }^{1}$ These authors contributed equally to this work.

${ }^{2}$ Corresponding author.

E-MAIL nsonen@med.mcgill.ca; FAX (514) 398-1287.

Article and publication are at www.genesdev.org/cgi/doi/10.1101/ gad. 887201 .
}

mRNA. eIF4E and eIF4G function as components of a trimeric complex, termed eIF4F, which also contains the RNA helicase eIF4A (Gingras et al. 1999b; Hershey and Merrick 2000; Fig. 1). eIF4G also establishes intermolecular contacts with several other components of the translational machinery, including the multisubunit, ribosome-associated initiation factor eIF3 (Hentze 1997; Hershey and Merrick 2000). Importantly, optimal binding of the $40 \mathrm{~S}$ ribosomal subunit is thought to require a region of single-stranded mRNA (Sonenberg 1993; Gingras et al. 1999b; Hershey and Merrick 2000). Thus, once eIF4F binds to the cap, eIF4A (in conjunction with an associated ubiquitous cofactor, eIF4B) is thought to unwind any inhibitory secondary structure present in the cap-proximal 5' untranslated region (5'UTR). Through its interaction with eIF3 and its ability to bind mRNA in a sequence nonspecific fashion, eIF4G bridges the mRNA to the 40S ribosomal subunit. Once the 40S subunit is bound to mRNA, the ribosome and associated factors are believed to scan in a $5^{\prime}$ to $3^{\prime}$ direction, until an initiation codon in the proper sequence context is encountered (Kozak 1989; Jackson 2000). When an initiation codon is recognized, and a codon/anticodon interaction established, the initiation factors dissociate from the small ribosomal subunit and allow for the joining of a 605 ribosomal subunit. In this way, a single ribosome is directed to a start codon, and protein synthesis can commence.

Treatment of cells with mitogens, hormones, or growth factors generally leads to an increase in translation. Conversely, nutrient deprivation or environmental stresses such as heat shock, osmotic shock, or UV irradiation generally reduce protein synthetic rates (for review, see Kleijn et al. 1998; Gingras et al. 1999b; Mathews et al. 2000; Schneider 2000). In mammalian cells, these changes in translation rates are often correlated with changes in the level or activity of eIF4F, resulting in differences in the rate of ribosomal recruitment to mRNA. That is, growing or stimulated cells contain high levels of eIF4F, whereas in quiescent or stressed cells low eIF4F levels are detected. Mammalian eIF4F formation is regulated by a family of translation repressors, the eIF4E binding proteins (4E-BPs; Lin et al. 1994; Pause et al. 1994). The 4E-BPs constitute a family of three small polypeptides that compete with eIF4G for 
Gingras et al.

Figure 1. eIF4F formation and ribosome recruitment. In resting, starved, or stressed cells, eIF4E is sequestered by the 4E-BPs (left). Following phosphorylation, 4E-BPs dissociate from eIF4E (1), allowing eIF4E to be incorporated into the eIF4F complex (2). Through eIF4E, eIF4F binds to the mRNA 5' cap structure (3). eIF4A (along with a cofactor, eIF4B) unwinds capproximal mRNA secondary structure in an ATP-dependent manner (4). The 40 S ribosomal subunit bound to eIF3 (and to a ternary complex consisting of eIF2, GTP and Met-tRNAi, shown as a triangle) is rethrough eIF4G (5). For further details, see Hershey and Merrick (2000). cruited to the single-stranded mRNA,
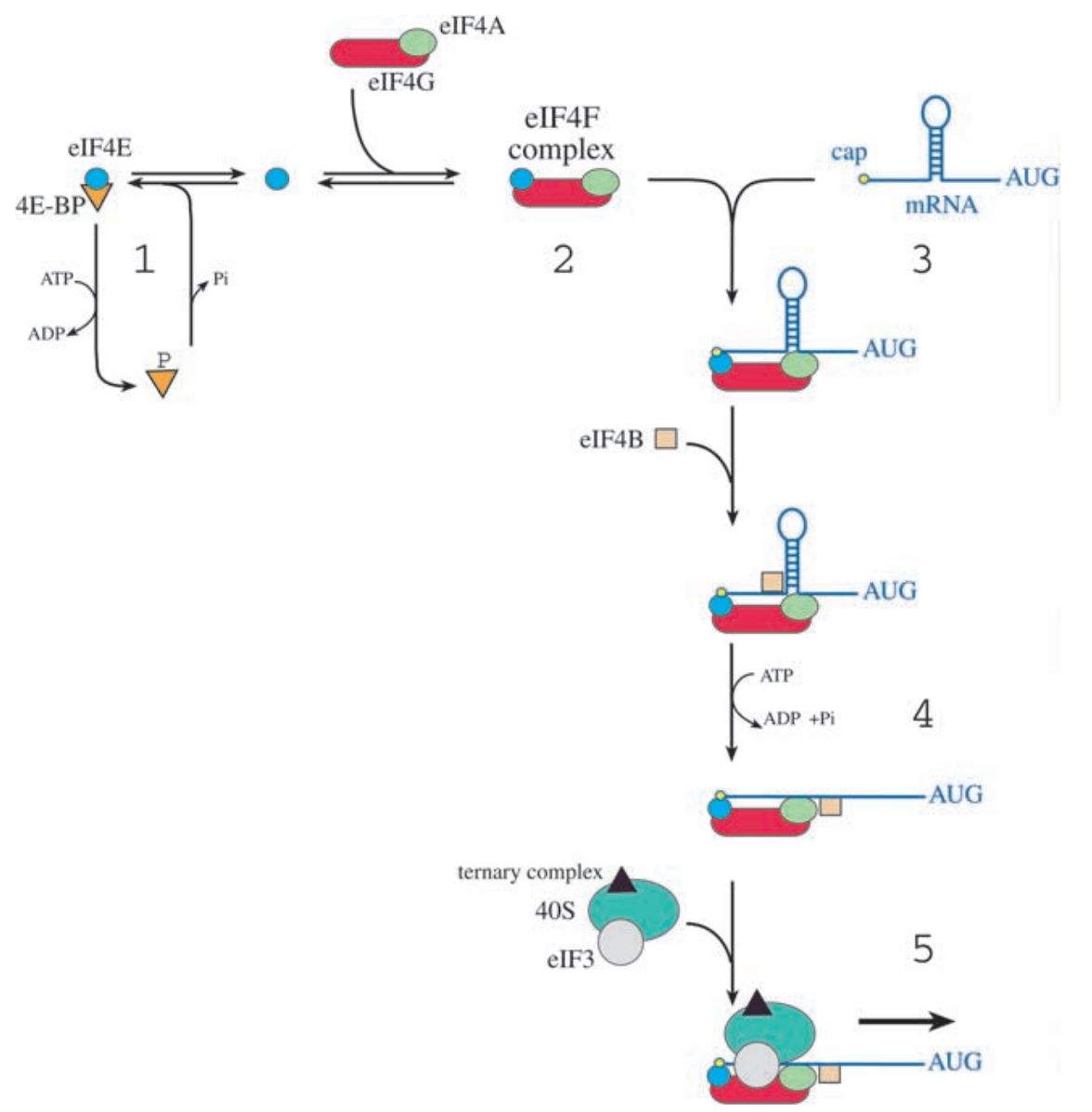

an overlapping binding site on eIF4E. Binding of 4E-BP or eIF4G to the convex dorsal surface of eIF4E is mutually exclusive. In fact, the cocrystal structures of 4E-BP bound to eIF4E, and an eIF4G fragment bound to eIF4E, indicate that the 4E-BPs act as molecular mimics of the eIF4E binding site in eIF4G (Marcotrigiano et al. 1999). Binding of the 4E-BPs to eIF4E is regulated by phosphorylation (Lin et al. 1994; Pause et al. 1994). Hypophosphorylated 4E-BPs bind avidly to eIF4E, but hyperphosphorylation of the 4E-BPs abrogates this interaction. As discussed in depth below, a basic understanding of the intracellular signaling pathways that modulate 4E-BP phosphorylation, the PI3K (phosphoinositide- $\underline{3}$ kinase) and FRAP/mTOR ( FKBP and rapamycin-associated pro-

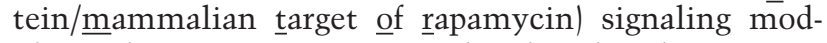
ules, is beginning to emerge. The phosphorylation state of eIF4G and eIF4B is also regulated by PI3K and FRAP/ mTOR signaling in mammalian cells, although it is not yet clear how phosphorylation alters the activity of these factors. Thus, several translation regulatory proteins are modulated in a concerted fashion by the same intracellular signaling pathways. This review is focused solely on how FRAP/mTOR signaling may effect changes in eIF4F activity. For detailed reviews on translation initiation, and the multitude of other mechanisms that contribute to its regulation, see Sonenberg et al. (2000).

\section{Global control of protein synthesis versus regulation of translation of individual mRNAs}

Whereas global changes in protein synthesis following hormone or growth factor stimulation are relatively small (up to twofold), a disproportionate and dramatic number of mRNAs is observed. How might different mRNA populations be regulated to different extents in response to a given stimuli or stress? As adumbrated more than 25 years ago by Lodish (1976), this is most likely due, in part, to the discriminatory activity of the general translation apparatus. One possible mechanism for this "translational discrimination," or "mRNA competition," is a significant disparity in the requirement of individual mRNAs for eIF4F helicase activity. Because 40S ribosomal subunit binding appears to require a region of single-stranded mRNA, cap-proximal 5'UTR secondary structure may be expected to reduce translational efficiency by rendering the mRNA less accessible to a ribosome, and/or by impeding the scanning process. When eIF4F helicase activity is low, translation of mRNAs that do not possess significant 5'UTR secondary structure would be expected to be affected to a lesser degree than mRNAs possessing more extensive 5'UTR secondary structure. Indeed, eIF4E overexpression prefincrease in the translation rates of a relatively small 
erentially enhances the translation of mRNAs with structured 5'UTRs (Koromilas et al. 1992), dominantnegative eIF4A mutant proteins preferentially inhibit translation of these poorly translated mRNAs in vivo (Svitkin et al. 2001), and eIF4B inactivation in yeast preferentially inhibits translation of reporter mRNAs possessing long and structured 5'UTRs (Altmann et al. 1995).

Many specific examples of mRNAs that are regulated in this fashion have been identified. For instance, whereas insulin stimulation increases global translation rates by $\sim$ twofold, the increase in the translation rate of the ornithine decarboxylase (ODC) mRNA, which possesses a relatively long, and highly structured 5'UTR, is 20- to 30-fold (Manzella et al. 1991). The ODC mRNA translational block can be relieved by removing 5'UTRstructured elements, or by overexpression of eIF4E (e.g., Manzella et al. 1991; Shantz et al. 1996). Many mRNAs coding for oncogenes or other proteins important for growth or proliferation control possess large, putatively highly structured 5'UTRs (Kozak 1991), and are thus predicted to be targets for translational discrimination. Consistent with this prediction, overexpression of eIF4E or eIF4G in rodent cells induces cellular transformation (see below; for review, see Hershey and Miyamoto 2000), and overexpression of eIF4E, eIF4G, and eIF4A has been noted in several different tumor types (see below).

Not all regulated mRNAs are controlled by the discriminatory activity of the general translation apparatus, however. Several different specific 5'- or 3'UTR sequence elements have also been demonstrated to modulate translational efficiency (for review, see Sonenberg et al. 2000). For instance, the $5^{\prime}$ terminal oligopyrimidine tract $\left(5^{\prime} \mathrm{TOP}\right)$ is a cap-proximal structural element (consisting of an uninterrupted stretch of 4-14 pyrimidines) that confers very stringent translation regulation. In conditions of nutrient deprivation, lack of growth factors, contact inhibition, or after initiation of a differentiation program, the translation of 5'TOP-containing mRNAs is potently repressed (Fumagalli and Thomas 2000; Meyuhas and Hornstein 2000).

The advent of cDNA array and DNA chip technologies has allowed for the determination of the number and nature of translationally regulated mRNAs in different cell types, and in response to distinct kinds of stimuli or stress (for review, see Carter et al. 2000). When applied to a sucrose density gradient, mRNAs that are actively translated sediment with heavy polysomes (mRNAs associated with several ribosomes), whereas mRNAs that are poorly translated (or not translated at all) are found in lighter fractions. By comparing these two mRNA populations in cells subjected to a stress or stimulus, those transcripts that are translationally activated (or inhibited) can be identified. For example, $\sim 1 \%$ of mRNAs (of the 1200 genes screened) in fibroblasts were found to shift to polysomes in response to serum-stimulation (Zong et al. 1999), whereas nearly 10\% of the transcripts (472 genes screened) were observed to be under translational control following activation of resting $\mathrm{T}$ cells (Mikulits et al. 2000). Following poliovirus infection (a condition in which little or no intact eIF4F is present and cellular protein synthesis is dramatically inhibited) $<3 \%$ of cellular mRNAs (200 of 7000) remain associated with heavy polysomes (Johannes et al. 1999).

Taken together, these data reinforce the view that in response to many types of stimuli or stress, global changes in protein synthesis are relatively modest, but the translation rates of a small population of mRNAs is dramatically modulated. This phenomenon likely involves several mechanisms, two of which are: (1) translational discrimination, due to differences in the requirement for eIF4F helicase activity and (2) a specific sequence element, the 5'TOP, which confers potent translational inhibition in starved or resting conditions. Intriguingly, both of these mechanisms are regulated by PI3K and FRAP/mTOR signaling.

\section{Rapamycin target proteins}

Rapamycin, a lipophilic macrolide, was isolated from a strain of Streptomyces hygroscopicus found in a soil sample from Easter Island (known by the inhabitants as Rapa Nui; Vezina et al. 1975). This compound potently inhibits yeast cell growth, as well as the proliferation of several types of mammalian cells, including $B$ and $T$ lymphocytes. Rapamycin treatment results in a $\mathrm{G}_{1}$ arrest in a variety of cell types and species (for review, see Abraham and Wiederrecht 1996; Schmelzle and Hall 2000). Because of its inhibitory effects on lymphocyte proliferation, rapamycin is a potent immunosuppressant, and effectively prevents allograft rejection (Abraham and Wiederrecht 1996; Kahan 2000, and references therein). Thus, rapamycin (and its analogs) is now used in the clinic, in conjunction with other immunosuppressants (reported by Bradley 1999). Rapamycin analogs have also been reported to inhibit several types of tumor cell growth, and are currently being tested in clinical trials (see below).

FKBP12 (FK506-binding protein, MW of $12 \mathrm{kD}$ ), an abundant, ubiquitously expressed protein of 108 amino acids (in humans), is the primary intracellular rapamycin receptor (Harding et al. 1989; Siekierka et al. 1989, 1990). FKBPs are peptidyl-prolyl cis/trans isomerases, catalyzing the interconversion of peptidyl-prolyl bonds, and are thus presumed to play a role in protein folding (for review, see Gothel and Marahiel 1999). Although rapamycin binding inhibits the isomerase activity of FKBP12 in vitro (Heitman et al. 1991b; Koltin et al. 1991; Wiederrecht et al. 1991), inhibition of this activity does not appear to be the cause of rapamycin sensitivity. In fact, deletion of the four yeast FKBP genes (termed FPR1-4, FPR1 being the FKBP12 homolog; for review, see Dolinski et al. 1997) is not lethal, and does not affect growth significantly. Rather, deletion of FPR1 confers recessive rapamycin-resistance, indicating that the presence of Fprlp (but not its catalytic activity) is required for rapamycin action (Heitman et al. 1991b; Koltin et al. 1991; Wiederrecht et al. 1991).

A subsequent genetic screen in $S$. cerevisiae for rapamycin-resistant mutants identified two genes, TOR1 
and TOR2 (target of rapamycin 1 and 2; also known as $D R R 1$ and $D R R 2$, for dominant rapamycin resistant), coding for two large proteins (>280 kD) sharing $67 \%$ identity at the amino acid level. Unlike the FKBPs, TOR mutants (which are point mutants, see below) act in a dominant manner (Heitman et al. 1991a; Cafferkey et al. 1993; Kunz et al. 1993; Helliwell et al. 1994; Lorenz and Heitman 1995). The curious results of the FPR1 deletion experiments were explained when Tor $1 \mathrm{p}$ and Tor $2 \mathrm{p}$ were demonstrated to interact with an Fprlp-rapamycin gainof-function complex (but not with Fprlp or rapamycin alone). Disruption of the TOR1 gene is not lethal, but leads to a slight decrease in cell growth rate (Helliwell et al. 1994), whereas disruption of TOR2 is lethal and is accompanied by random arrest throughout the cell cycle (Kunz et al. 1993). Strains disrupted for both TOR1 and TOR2 recapitulate the phenotype observed with rapamycin treatment, in which cells arrest in $\mathrm{G}_{1}$ within one generation (Kunz et al. 1993; Helliwell et al. 1994). Taken together, these data indicate that Tor function (provided by either Torlp or Tor $2 \mathrm{p}$ ) is necessary for $\mathrm{G}_{1}$ progression. The lethality of the TOR2 deletion is not restored by overexpression of wild-type or rapamycinresistant TOR1 proteins (Zheng et al. 1995), indicating that Tor $2 p$, in addition to a rapamycin-inhibitable activity, also possesses a rapamycin-resistant activity that is essential and not shared with Torlp (Kunz et al. 1993; Zheng et al. 1995). The Tor2p-specific function appears to be linked to cell cycle-dependent organization of the actin cytoskeleton, which is disrupted in a tor2 mutant (Schmidt et al. 1996, 1997).

A mammalian homolog of the Tor proteins was purified and cloned from various species, and alternatively termed FRAP, mTOR, RAFT (rapamycin and FKBP12 target), SEP (sirolimus effector protein), and RAPT (rapamycin target; Brown et al. 1994; Chen et al. 1994; Chiu et al. 1994; Sabatini et al. 1994; Sabers et al. 1995). Here we refer to the mammalian protein as FRAP/mTOR. FRAP/mTOR is $289 \mathrm{kD}$ and shares $45 \%$ identity with the yeast Tor proteins (Brown et al. 1994; Sabatini et al. 1994; Sabers et al. 1995). Only one homolog has been found in mammals, and the human, rat, and mouse FRAP $/ \mathrm{mTOR}$ proteins share $>95 \%$ identity at the amino acid level (for review, see Abraham and Wiederrecht 1996).

\section{Modular structure of the Tors and FRAP/mTOR}

The Tor and FRAP/mTOR proteins possess a carboxyterminal region sharing significant homology with lipid kinases (especially with PI3 kinases, and with weaker similarity to PI4 kinases). Based on this homology, the Tors and FRAP/mTOR have been assigned to a larger protein family termed the PIKKs (phosphoinositide kinaserelated kinases). In mammalian cells, the PIKK family is comprised of FRAP/mTOR, ATM (ataxia telangiectasia mutated), ATR/FRP (ataxia telangiectasia and $\underline{\text { Rad} 3}$ related; also known as FRP for FRAP-related protein), and DNA-PKc (DNA-activated protein kinase, ㄸatalytic

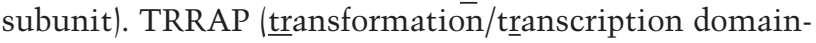

associated protein) also exhibits significant homology to the PIKKs, but it lacks conserved residues in its catalytic domain, and is therefore not expected to possess kinase activity. Most PIKKs are conserved from yeast to mammals, with the exception of the DNA-PKc protein, which appears to be restricted to vertebrates. PIKK family members are very large proteins, all of which have been posited to be involved in cell cycle checkpoint control.

In addition to the lipid kinase homology domain, all PIKKs also possess a short segment at their extreme carboxyl terminus not present in PI3 and PI4 kinases, termed FATC (for FRAP, ATM, and TRRAP, carboxyterminal homology domain), and a region of weaker homology termed the FAT domain (between amino acids 1382-1982 in the human FRAP/mTOR; Alarcon et al. 1999; Bosotti et al. 2000). Because the FAT domain is always found in combination with the FATC region, intramolecular interactions between FAT and FATC have been postulated to modulate kinase activity. The Tor FAT domain was also described independently as a "toxic effector domain," which inhibits yeast growth when overexpressed. How this portion of Tor confers a toxic effect in yeast is unknown, although it is presumed to interfere with the activity of the endogenous Tor by titrating out an effector or activator (Alarcon et al. 1999).

Immediately amino-terminal to the kinase domain (and downstream of the FAT domain), lies the FKBP12rapamycin binding (FRB) domain (Cafferkey et al. 1993, 1994; Kunz et al. 1993; Helliwell et al. 1994). The structure of the FRB domain complexed with FKBP12 and rapamycin has been determined by X-ray crystallography, and reveals that rapamycin simultaneously occupies two hydrophobic pockets, one in FKBP12 and the other in FRAP/mTOR (Choi et al. 1996). Although limited interactions occur between the two proteins, rapamycin establishes several contacts with both polypeptides, and is thus able to induce an FKBP12-FRAP/ mTOR interaction (Choi et al. 1996). The yeast Tor mutants selected in the original genetic screens for rapamycin resistance possess mutations at Ser 1972 or Ser 1975 (in Tor1p and Tor2p, respectively, corresponding to Ser 2035 in FRAP/mTOR). Mutation of this serine to bulkier residues (isoleucine, threonine, or glutamic acid) engenders rapamycin-resistance, whereas mutation of this serine to alanine, a smaller amino acid, does not affect rapamycin binding. The structure of the FRB domain complexed with FKBP12 and rapamycin explains the requirement for a small residue at this position, as a bulkier residue would be expected to prevent rapamycin binding in the hydrophobic pocket (Choi et al. 1996).

The first 1200 amino acids of the Tor and FRAP/ mTOR proteins comprise a "HEAT" domain /named for Huntingtin, elongation factor 3 , the regulatory $\underline{\text { A subunit }}$ of PP2A and Torlp, the first proteins found to possess such a motif; Andrade and Bork 1995; Groves and Barford 1999; Groves et al. 1999). This motif consists of stretches of $\sim 40$ amino acids in at least three repeats, and displays a consensus pattern of hydrophobic, proline, aspartic acid, and arginine residues. HEAT repeats have also been 
described in several other proteins (including eIF4G; Marcotrigiano et al. 2001), many of which function as adapters or scaffolds. HEAT domains form curved rods consisting of $\alpha$-loop- $\alpha$ repeats, providing a large hydrophobic surface area for protein-protein interactions (Chook and Blobel 1999; Cingolani et al. 1999; Groves et al. 1999; Vetter et al. 1999; Marcotrigiano et al. 2001).

A protein termed gephyrin interacts with a region of the FRAP/mTOR HEAT domain (amino acids 10171046; Sabatini et al. 1999). Gephyrin is a tubulin-binding protein involved in postsynaptic clustering of neuronal glycine receptors, and is presumed to modulate the intracellular localization of FRAP/mTOR. Mutations that abrogate gephyrin binding also prevent FRAP/mTOR signaling to two downstream translational targets, the ribosomal S6 kinase 1 (S6K1) and 4E-BP1 (see below; Sabatini et al. 1999). In yeast, the HEAT repeats are responsible for localization of Tor2 $p$ to the plasma membrane, most likely through protein-protein interactions with membrane-associated proteins (Kunz et al. 2000).

\section{FRAP/mTOR kinase activity and a putative signaling mechanism}

FRAP/mTOR, despite its homology to PI3Ks, functions as a protein kinase. Endogenous FRAP/mTOR, or FRAP/ mTOR expressed in insect cells, autophosphorylates on Ser 2481 (Brown et al. 1995; Peterson et al. 2000). FRAP/ mTOR immunoprecipitates can phosphorylate several other protein targets in vitro, including S6K1, 4E-BP1, and 4E-BP2 (for review, see Fumagalli and Thomas 2000; Raught et al. 2000b). Protein kinase activity is required for FRAP/mTOR function. Mutations at positions corresponding to those that abolish the lipid kinase activity of PI3Ks prevent FRAP/mTOR autophosphorylation, and abrogate its ability to signal to S6K1 and 4E-BP1 (e.g., Brown et al. 1995; Brunn et al. 1997b).

Wortmannin and LY294002 are structurally unrelated molecules that, at low concentrations, are relatively specific, cell-permeable PI3K inhibitors (Powis et al. 1994; Vlahos et al. 1994; Ui et al. 1995). However, wortmannin also directly inhibits FRAP/mTOR autokinase activity with an $\mathrm{IC}_{50}$ that is $\sim 100$-fold higher than that required for PI3K inhibition ( $200 \mathrm{nM}$ in vitro, $300 \mathrm{nM}$ in vivo; Brunn et al. 1996). LY294002 inhibits FRAP/mTOR autokinase activity in vitro with an $\mathrm{IC}_{50}$ of $5 \mu \mathrm{M}$ (Brunn et al. 1996). The other mammalian members of the PIKK family are also sensitive to wortmannin treatment, with ATM and DNA-PKc being more sensitive than ATR (Hartley et al. 1995; Sarkaria et al. 1998). Thus, PIKK inhibition by wortmannin and LY294002 must be considered when analyzing the effects of these inhibitors: In some cases, effects that have been attributed to PI3K inhibition may actually be caused by inhibition of one or more PIKKs.

Although rapamycin complexed with FKBP12 potently inhibits downstream signaling by FRAP/mTOR in vivo, whether this complex inhibits the kinase activity of $\mathrm{FRAP} / \mathrm{mTOR}$ remains a controversial issue. It was reported that the modest increase in FRAP/mTOR activ- ity elicited by insulin (see below) can be blocked by rapamycin (Scott et al. 1998). Rapamycin in combination with FKBP12 does inhibit FRAP/mTOR autokinase activity in vitro, but a much higher concentration of rapamycin than is required in vivo is necessary to observe this effect (Peterson et al. 2000, and references therein). Addition of rapamycin to cells in culture fails to inhibit FRAP/mTOR autophosphorylation in vivo at Ser 2481, as determined by the use of a phosphospecific antibody directed against this site (Peterson et al. 2000), and little or no difference in the kinase activity of FRAP/mTOR immunoprecipitates is detected after rapamycin treatment (Peterson et al. 2000, and references therein). Finally, whereas a mutation in the kinase domain of the yeast Tor $2 p$ is lethal, rapamycin treatment leads to $G_{1}$ arrest. If rapamycin were to inhibit Tor $2 \mathrm{p}$ kinase activity, rapamycin treatment and mutation of the Tor2p kinase domain would be expected to evoke equivalent phenotypes. Taken together, these data raise the distinct possibility that rapamycin does not effect a direct inhibition of the kinase activity of Tor and FRAP/mTOR.

One alternative model is that binding of the FKBPrapamycin complex to $\mathrm{FRAP} / \mathrm{mTOR}$ triggers the activation of a phosphatase, which then acts on downstream FRAP/mTOR effector molecules. Genetic screening has identified several phosphatases, and a phosphatase-associated protein, as part of a rapamycin-sensitive signaling pathway in S. cerevisiae (Di Como and Arndt 1996; Jiang and Broach 1999). S. cerevisiae expressing mutants of Tap42p (a protein that interacts directly with the catalytic subunit of the phosphatases PP2A and Sit4p) exhibit a dramatic defect in translation initiation (Di Como and Arndt 1996). Phosphorylated Tap42p competes with the adaptor (A) and regulatory (B) subunits of PP2A for binding to the catalytic subunit, but dephosphorylated Tap42p cannot compete efficiently (Jiang and Broach 1999). Phosphorylation of Tap $42 p$ is effected through the Tor proteins, as the rapamycin sensitivity of Tap42p phosphorylation is abrogated in a yeast strain expressing a rapamycin-resistant mutant of Torlp (Jiang and Broach 1999). Furthermore, immunoprecipitates of Tor2p can phosphorylate Tap42p in vitro (Jiang and Broach 1999). Dephosphorylation of Tap42p is mediated by the trimeric PP2A complex (Jiang and Broach 1999). Consistent with this, the association of Tap42p with PP2A is disrupted by nutrient deprivation or rapamycin treatment, most likely through dephosphorylation of Tap42p (Di Como and Arndt 1996; Jiang and Broach 1999|. An ortholog of Tap42p, the B cell receptor-binding protein $\alpha 4$, has been identified in mammalian cells (Inui et al. 1995). An interaction between $\alpha 4$ and phosphatases is also conserved in mammals; $\alpha 4$ binds directly to the catalytic subunits of PP2A (Murata et al. 1997; Inui et al. 1998), PP4, and PP6 (Chen et al. 1998; Nanahoshi et al. 1999). Like Tap42p, $\alpha 4$ is a phosphoprotein, and the $\alpha 4-$ phosphatase interaction is inhibited by rapamycin (Murata et al. 1997; Inui et al. 1998). These observations have led to a model predicting that Tap42p (or $\alpha 4$ ) phosphorylation, and PP2A binding, is regulated by Tor (or FRAP/ mTOR) signaling. An inhibition in Tor (FRAP/mTOR) 
signaling could lead to dephosphorylation of Tap42p $(\alpha 4)$, dissociation of the Tap42p ( $\alpha 4)$-phosphatase complex, and phosphatase activation (Fig. 2; Di Como and Arndt 1996; Schmidt et al. 1998; Beck and Hall 1999; Jiang and Broach 1999).

\section{Does the phosphoinositide-3 kinase pathway signal to FRAP/mTOR?}

The PI3K signaling pathway has been described in detail elsewhere (Fruman et al. 1998), and thus will be only briefly summarized here. The PI3Ks are lipid kinases that phosphorylate the third position in the inositol ring (this discussion applies to class I PI3Ks; for review, see Fruman et al. 1998). Phosphorylated lipids act as second messengers to recruit and activate downstream targets, including the serine/threonine kinase Akt/PKB (protein kinase $\underline{B}$; see below). PTEN (phosphatase and tensin homolog deleted from chromosome 10; also known as MMAC, mutated in multiple advanced cancers; or TEP, TGF $\beta$-regulated and epithelial cell-enriched phosphatase) is a lipid phosphatase that dephosphorylates PI3K lipid products and thus negatively regulates PI3K signaling (Fig. 3; for review, see Cantley and Neel 1999; Di Cristofano and Pandolfi 2000).

Akt/PKB (a family of three members in mammals) possesses at its amino terminus a pleckstrin homology $(\mathrm{PH})$ domain that specifically binds PI3K lipid products (for review, see Chan et al. 1999). After lipid binding, Akt/ $\mathrm{PKB}$ is targeted to membranes where it is phosphorylated and activated by the kinase PDK1 (thought to be constitutively membrane localized) and a kinase activity termed PDK2 (Chan et al. 1999). Artificial membrane targeting of Akt/PKB (accomplished, for example, by the fusion of an amino-terminal myristylation signal) results in constitutive kinase activation. Akt/PKB has been implicated in a variety of cellular processes, including cell growth and proliferation, protection from apoptosis, and regulation of gene expression, including translational control (for review, see Chan et al. 1999; Gingras et al. 1999b).

Another PI3K effector that has been implicated in the control of translation initiation is S6K (two homologs in mammals). S6Ks phosphorylate the ribosomal protein S6, and possibly the translation initiation factor eIF4B (see below; for review, see Fumagalli and Thomas 2000; Hershey and Merrick 2000). Activation of S6K1 is a complex, multistep mechanism (for review, see Fumagalli and Thomas 2000). Like Akt/PKB, S6K activity is inhibited by wortmannin and LY294002 (for review, see Thomas and Hall 1997). Activation of S6K was also demonstrated to require direct phosphorylation by PDK1 (Pullen et al. 1998). However, S6K activity is also potently inhibited by rapamycin, indicating that both PI3K and FRAP/mTOR signaling are required for its activation (for review, see Thomas and Hall 1997). Intriguingly, the $\mathrm{PI} 3 \mathrm{~K}$ and FRAP/mTOR inputs to S6K can be separated. Deletion of an amino-terminal fragment of S6K1 confers rapamycin resistance, yet this truncation mutant remains sensitive to wortmannin treatment. Deletion of both the amino- and carboxyl termini of S6K confers resistance to rapamycin and wortmannin (Dennis et al. 1996; Mahalingam and Templeton 1996). These data argue against a linear pathway comprised of PI3K and FRAP/mTOR, but instead suggest that two separate inputs are required for full activation of S6K, such that a disruption in either of the two signaling pathways can abrogate S6K activity. A role for the atypical PKC isoforms in the activation of S6K1 also was described recently (for review, see Fumagalli and Thomas 2000).

The S6K studies suggested that FRAP/mTOR does not lie directly downstream of PI3K. The roles of growth factors and various components of the PI3K pathway in the regulation of FRAP/mTOR activity were thus inves-

Figure 2. A putative mechanism for Tor (FRAP/ mTOR) signaling in response to nutrient levels. In conditions of nutrient availability $(1$, left), Tor (or FRAP/mTOR) maintains Tap42p (or $\alpha 4$ ) in a phosphorylated state. Phosphorylation induces a direct interaction with the catalytic (C) subunit of PP2A. Interaction of Tap42p (or $\alpha 4$ ) with $\mathrm{PP}_{2} \mathrm{~A}_{\mathrm{C}}$ prevents association with the adaptor (A) and regulatory (B) subunits, and thus inhibits dephosphorylation of downstream PP2A targets. In the absence of nutrients $(2$, right), or in cells treated with rapamycin (3), Tor (FRAP/mTOR) does not signal to Tap42p (or $\alpha 4$ ), resulting in Tap42p (or $\alpha 4$ ) dephosphorylation, and loss of PP2 $\mathrm{A}_{\mathrm{C}}$ binding activity. $\mathrm{PP} 2 \mathrm{~A}_{\mathrm{C}}$ is then free to associate with the $\mathrm{A}$ and $\mathrm{B}$ subunits, and to dephosphorylate downstream targets, resulting in translation inhibition. Because loss of TOR also leads to phosphatase activation (4, right), Tor (FRAP/mTOR) likely signals constitutively in the presence of nutrients, whereas in the absence of nutrients it is inactive (resulting in no signal). For clarity, only the association of Tap42p $(\alpha 4)$ with $\mathrm{PP}_{\mathrm{C}}$ is indicated; it can also associate with other phosphatases (see text for details).

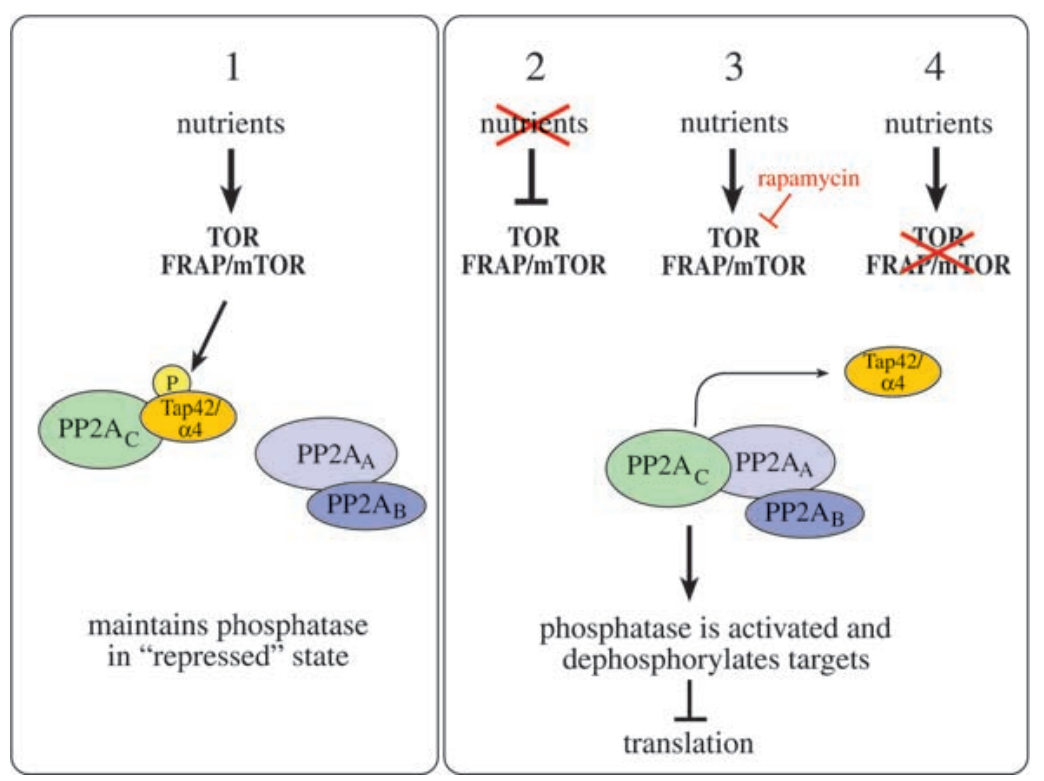




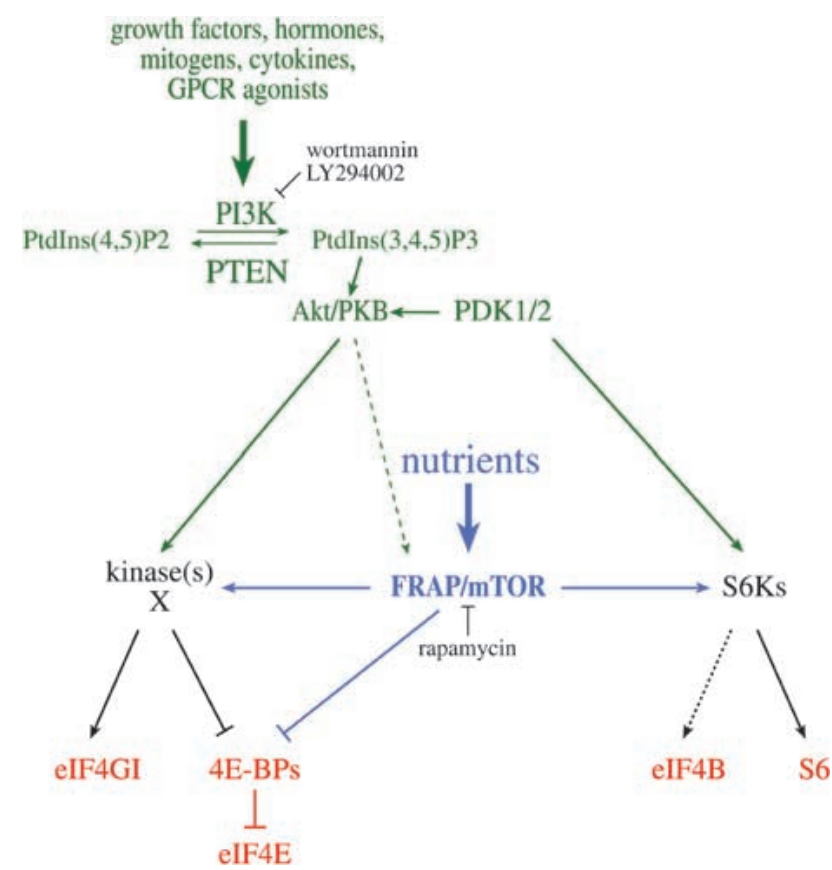

Figure 3. Activation of translation initiation factors and inhibitors by PI3K and FRAP/mTOR signaling. Activated PI3K phosphorylates phosphatidylinositols (PtdIns). The reverse reaction is mediated by the phospholipid phosphatase PTEN. PI3K-generated lipid products target Akt/PKB to membranes. The membrane-proximal kinases PDK1 and PDK2 activate Akt/ $\mathrm{PKB}$, which transmits its signal to unknown kinase(s) $\mathrm{X}$, and possibly to FRAP/mTOR. Kinase(s) X phosphorylates eIF4GI and the 4E-BPs, repressing the 4E-BPs and possibly activating eIF4GI. PDK1 also phosphorylates and activates S6Ks. FRAP/ mTOR acts as a nutrient-sensor. When sufficient nutrients are available, FRAP/mTOR transmits a positive signal to the S6Ks and kinase (s) X, and participates in the inactivation of the 4EBPs. These events result in the activation of the translation of specific mRNA subpopulations. When nutrients are scarce (or in the presence of rapamycin), FRAP/mTOR does not signal. The dashed lines indicate possible links. The pathway activated by extracellular stimuli is shown in green, whereas nutrientregulated signaling is indicated in blue. Translational effectors are depicted in red. GPCR $=$ G-protein coupled receptor. The targets of inhibition by wortmannin, LY294002, and rapamycin are indicated. For clarity, the signaling downstream of FRAP/ mTOR by phosphatases is not depicted.

tigated directly. Following growth factor treatment, or in response to expression of a constitutively active Akt/ PKB molecule, FRAP/mTOR immunoprecipitates display only a modest increase (or no change at all) in kinase activity in vitro (Scott and Lawrence 1998; Scott et al. 1998; Sekulic et al. 2000). In fact, FRAP/mTOR kinase activity in immunoprecipitates is constitutively active, even when isolated from cells deprived of growth factors. This is in contrast to the dramatic increase in S6K activity observed in vivo following stimulation of the same cells by the same growth factors (Fumagalli and Thomas 2000). It could be argued that the FRAP/mTOR immunoprecipitation and in vitro kinase assay do not accurately reflect the in vivo situation (due, for example, to the loss of an inhibitor or to an artificial activation of the kinase during immunoprecipitation). Thus, the existence of a direct link between Akt/PKB and FRAP/ mTOR was also investigated. Phosphospecific antibodies to putative Akt/PKB phosphorylation sites in FRAP/ mTOR were utilized to monitor the influence of the PI3K pathway on FRAP/mTOR phosphorylation. One site, Ser 2448, was found to be phosphorylated in vivo. Addition of insulin or interleukin-3 increased Ser 2448 phosphorylation in a PI3K- and Akt/PKB-dependent manner (Navé et al. 1999; Sekulic et al. 2000). However, the relevance of this phosphorylation to FRAP/mTOR activity is not clear, because a FRAP/mTOR mutant protein possessing an alanine substitution at this site is able to fully activate S6K1 following growth factor stimulation (Sekulic et al. 2000).

Taken together, these data suggest that FRAP/mTOR activity is not directly regulated by PI3K signaling. PI3K and FRAP/mTOR signaling are both clearly required, however, for activation of S6K1 and other downstream targets (see below). How these signals may be integrated remains unknown, but (as discussed below) a role for FRAP/mTOR (and Tor) in nutrient sensing is gaining widespread acceptance. This model suggests that Tor/ FRAP/mTOR relays a signal to downstream targets only in the presence of sufficient nutrients, and thus serves as a nutrient-dependent "gatekeeper."

\section{Effects of rapamycin on translation rates in yeast}

In yeast, rapamycin treatment leads to a precipitous translational arrest, accompanied by polysome disaggregation (Barbet et al. 1996). The translational arrest occurs prior to, and is presumed to be the cause of, cell cycle arrest in $\mathrm{G}_{1}$ (Barbet et al. 1996), which could be caused by inhibition of cyclin 3 (CLN3) mRNA translation. Cln3p activates the transcription of late $\mathrm{G}_{1}$-specific genes, including CLN1 and CLN2, and is subject to translational control (Polymenis and Schmidt 1997). CLN3 mRNA translation is rapidly repressed following rapamycin treatment or nitrogen deprivation (Gallego et al. 1997). The cycle arrest (but not the general decrease in translation initiation) can be overcome if the CLN3 coding sequence is fused to the promoter and 5'UTR of the polyubiquitin-encoding gene UBI4, which renders CLN3 translation less dependent on the cap. Consistent with this, in $S$. cerevisiae mutants defective in eIF4E (which also arrest in $\mathrm{G}_{1}$ ), expression of CLN3 is sufficient to restore progression through the $G_{1}$ to $S$ phase transition (Danaie et al. 1999).

\section{Effects of rapamycin on translation rates in mammalian cells}

Many of the same mRNAs that respond to hormone and growth factor stimulation are extremely sensitive to rapamycin treatment (e.g., Pedersen et al. 1997). The best studied example of rapamycin-sensitive mRNAs is the class possessing a 5'TOP (Jefferies et al. 1994; Terada et 
al. 1994). Most 5'TOP-containing mRNAs code for components of the translation machinery, such as ribosomal proteins, elongation factors, and the poly(A) binding protein (for review, see Jefferies and Thomas 1996; Meyuhas et al. 1996; Meyuhas and Hornstein 2000). Translation of these mRNAs is modulated through S6K1, as overexpression of a rapamycin-resistant form of S6K1 protects eEF1 $\alpha$ (eukaryotic elongation factor $\underline{1 \alpha}$, a 5'TOP-containing mRNA) from the effects of rapamycin (Jefferies et al. 1997). Conversely, overexpression of a kinase dead (dominant-negative) S6K1 prevents translational upregulation after mitogen treatment (Jefferies et al. 1997). How S6K1 modulates 5'TOP translation is not understood. For many years the ribosomal S6 protein was the only known S6K1 target. It was therefore postulated that 5'TOP translation was regulated through S6 phosphorylation. However, a direct proof for the involvement of S6 in 5'TOP mRNA translation control is lacking. It is noteworthy that 5'TOP translation during early Xenopus embryogenesis is regulated by $\mathrm{S} 6 \mathrm{~K}$, but not by the ribosomal S6 protein. In this system, 5'TOP mRNAs are rapamycin-sensitive, but $\mathrm{S} 6$ phosphorylation is unaffected by rapamycin (Schwab et al. 1999). Whether this is an isolated case remains to be established.

A few examples of rapamycin-sensitive non-5'TOP mRNAs have also been identified. Rapamycin-sensitivity of the translation of some mRNAs could be mediated by the binding of specific mRNA binding proteins to cis-acting elements. For example, the mRNA coding for IGF-II leader 3 is found in inactive messenger ribonucleoproteins (mRNPs) in resting cells, but its translation is induced in growing cells in a rapamycin-sensitive manner (Nielsen et al. 1995). This regulation is conferred by the 5'UTR, because translation of IGF-II leader 4, which differs only in the 5'UTR, is constitutive (Nielsen et al. 1995). One possible mechanism for this regulation is via the binding of a family of inhibitory proteins in the 5'UTR of the IGF-II leader 3 (and not to the leader 4; Nielsen et al. 1999).

A third category of rapamycin-sensitive mRNAs are those presumed to require high amounts of eIF4F helicase activity, due to the presence of long, structured 5'UTRs (as described above). Indeed, the translation of two such mRNAs, those coding for ODC and c-myc, is strongly inhibited by rapamycin treatment (e.g., Seidel and Ragan 1997; Pyronnet et al. 1998; West et al. 1998). Several other mRNAs whose translation is specifically affected by rapamycin (including Bcl3, GLUT1, and Cyclin D1) have also been identified (e.g., Muise-Helmericks et al. 1998; Weyrich et al. 1998; Taha et al. 1999), but the mechanism mediating the rapamycin-sensitivity of these transcripts remains to be established. As discussed previously, a genomic-based approach will be necessary to obtain a clearer picture of the prevalence and identity of rapamycin-sensitive mRNAs.

\section{FRAP/mTOR signals to translation initiation effectors}

The phosphorylation of the S6Ks, two eIF4 proteins (eIF4GI and eIF4B), and the translational inhibitors 4E-
BP1 and 4E-BP2 is modulated by PI3K and FRAP/mTOR signaling (illustrated in Fig. 3). The effects of rapamycin on translation have thus been postulated to be due, in part, to modulation of the activity of these factors. Note that, in addition to its effects on initiation factors, rapamycin also affects phosphorylation of the elongation factor eEF2 (for review, see Proud 2000).

\section{$4 E-B P S$}

Phosphorylation of specific serine and threonine residues modulates the affinity of the 4E-BPs for eIF4E (e.g., Lin et al. 1994; Pause et al. 1994; Fadden et al. 1997). Whereas hypophosphorylated 4E-BPs bind efficiently to eIF4E, phosphorylation of a critical set of residues abrogates this interaction (for review, see Raught et al. 2000b). 4E-BP phosphorylation levels are increased by many types of extracellular stimuli, including hormones, growth factors, cytokines, mitogens, and G-protein coupled receptor agonists (Gingras et al. 1999b). Conversely, environmental or nutritional stresses, as well as infection with certain picornaviruses, decrease 4E-BP1 phosphorylation (Gingras et al. 1999b). Rapamycin treatment decreases 4E-BP1 phosphorylation, and increases its affinity for eIF4E (Lin et al. 1995; Beretta et al. 1996a; von Manteuffel et al. 1996). The sensitivity of the various phosphorylation sites to rapamycin mirrors the sensitivity of these sites to serum starvation, or treatment with inhibitors of PI3K (for review, see Raught et al. 2000b). In HEK293 cells, Thr 37 and Thr 46 are phosphorylated even in the absence of serum, and serum stimulation only mildly increases phosphorylation of these sites (Gingras et al. 1999a). Phosphorylation of Thr 37 and Thr 46 is also relatively resistant to inhibition by rapamycin (Gingras et al. 1999a). However, phosphorylation of Ser 65 and Thr 70 is strongly enhanced by the addition of serum, and nearly abolished following rapamycin treatment. 4E-BP1 phosphorylation is an ordered, hierarchical process (Gingras et al. 1999a). Mutation of Thr 37 and/or Thr 46 to alanine(s) prevents phosphorylation of Ser 65 and Thr 70, but mutation of Thr 37 and Thr 46 to glutamic acid residues partially restores the phosphorylation of Ser 65 and Thr 70, indicating that phosphorylation of Thr 37 and Thr 46 serves as a requisite "priming" event (Gingras et al. 1999a; Mothe-Satney et al. 2000a,b; A-C. Gingras and B. Raught, unpubl.).

FRAP/mTOR immunoprecipitates phosphorylate 4EBP1 on the "priming" sites, Thr 37 and Thr 46 (Brunn et al. 1997a,b; Burnett et al. 1998; Gingras et al. 1999a; Heesom and Denton 1999/. However, FRAP/mTOR clearly plays a critical regulatory role in the phosphorylation of Ser 65 and Thr 70, because these residues display a higher degree of rapamycin sensitivity than Thr 37 and Thr 46, and expression of a rapamycin-resistant $\mathrm{FRAP} / \mathrm{mTOR}$ protein (but not rapamycin-resistant S6K1) confers rapamycin resistance to 4E-BP1 phosphorylation at these sites (Brunn et al. 1997b; Hara et al. 1997; von Manteuffel et al. 1997; Gingras et al. 1998). Because treatment of cells with the phosphatase inhibitor calyculin prevents 4E-BP1 dephosphorylation (Peterson et al. 
1999), it is possible that a PP2A-type phosphatase directed towards Ser 65 and Thr 70 is activated following rapamycin treatment. Consistent with this hypothesis, Tap42 and $\alpha 4$ interfere with PP2A-induced 4E-BP1 dephosphorylation in an in vitro assay (Nanahoshi et al. 1998).

The signaling pathway to 4E-BP1 also involves, in most circumstances, activation of $\mathrm{PI} 3 \mathrm{~K}$ and $\mathrm{Akt} / \mathrm{PKB}$ (e.g., von Manteuffel et al. 1996; Gingras et al. 1998; Kohn et al. 1998; Wu et al. 1998; Takata et al. 1999), although PI3K and Akt-independent phosphorylation has been reported (Rybkin et al. 2000). Wortmannin and LY294002 inhibit Ser 65 and Thr 70 phosphorylation at low concentrations. Overexpression of a constitutively active $\mathrm{p} 110 \alpha$ PI3K catalytic subunit or the Akt/PKB protein maintains phosphorylation at Ser 65 and Thr 70, even in the absence of serum or mitogens (Gingras et al. 1998; Kohn et al. 1998; Dufner et al. 1999; Takata et al. 1999). Thus, like S6K1, both FRAP/mTOR and PI3K signaling regulate 4E-BP1 phosphorylation.

In 293 cells, the major phosphorylation sites are Thr 37, Thr 46, Ser 65, Thr 70, and Ser 83 (it is unclear, however, whether Ser 83 phosphorylation is modulated by extracellular stimuli). Another phosphorylation site, Ser 112 (which is rapamycin-resistant, but wortmanninsensitive, and which was reported to be a major phosphorylation site in adipocytes) has also been identified (Heesom et al. 1998). Ser 112 was reported to be a target for ATM (Yang and Kastan 2000). Putative roles for PKC $\delta$ and c-abl in activating 4E-BP1 phosphorylation were also reported recently, although the mechanisms involved in this process remain to be established (Kumar et al. 2000a,b).

4E-BP2 shares $56 \%$ identity with $4 \mathrm{E}-\mathrm{BP} 1$, the strongest homology occurring in the region surrounding the eIF4Ebinding site. Why mammalian cells possess multiple 4EBPs, each with apparently identical function, is unknown. However, some interesting differences between the 4E-BP isoforms are beginning to emerge. Like 4E$\mathrm{BP} 1,4 \mathrm{E}-\mathrm{BP} 2$ phosphorylation is sensitive to LY294002 and rapamycin treatment. However, 4E-BP2 appears to be phosphorylated on fewer residues than 4E-BP1 (B. Raught and A-C. Gingras, unpubl.). Whereas human 4E$\mathrm{BP} 1$ is separated into six isoforms in the isoelectric focusing gel system (A-C. Gingras and B. Raught, unpubl.), 4E-BP2 is separated into only four species. This difference in the number of phosphorylated residues may affect the binding properties of 4E-BP2: Although 4E-BP1 is rapidly released from eIF4E in response to adenovirus infection, 4E-BP2 is released much more slowly (Gingras and Sonenberg 1997). Thus, the kinetics of eIF4E liberation after the application of a given stimulus could vary significantly in different tissues containing dissimilar 4E-BP1/4E-BP2 ratios (e.g., Lin and Lawrence 1996).

\section{eIF4GI}

eIF4GI phosphorylation is also regulated by PI3K and FRAP/mTOR signaling. Three phosphorylation sites (serines 1108, 1148, and 1192) have been identified in an
eIF4GI carboxy-terminal "hinge" region, located between the "core" middle fragment (a HEAT domain that interacts with eIF3, eIF4A, and which binds to RNA; Lamphear et al. 1995; Imataka and Sonenberg 1997; Marcotrigiano et al. 2001) and the modulatory carboxy-terminal region (a domain possessing a second binding site for eIF4A, and which interacts with the eIF4E kinase, Mnk1; Imataka and Sonenberg 1997; Morino et al. 2000). Phosphorylation of these sites is up-regulated by serum or insulin treatment, and is inhibited by rapamycin or LY294002 (Raught et al. 2000a). However, neither FRAP/ mTOR nor S6K1 can directly phosphorylate the carboxyterminal hinge region residues in vitro. Interestingly, amino-terminally truncated eIF4GI proteins are constitutively phosphorylated on the hinge region residues, even in the presence of rapamycin (Raught et al. 2000a). Thus, rapamycin-insensitive kinases must be responsible for the phosphorylation of these residues, whereas an amino-terminal fragment regulates the accessibility of the hinge region sites to these kinases in a rapamycinsensitive manner. The function of these phosphorylation events is unclear. The hinge region phosphorylation sites do not overlap with binding sites for any known eIF4GI interacting protein, and no differences in the interaction of eIF4GI with several known binding partners (eIF4A, eIF3, and Mnk1; Raught et al. 2000a) were observed for eIF4GI isolated from serum-starved versus serum-stimulated cells. It was thus suggested that phosphorylation could affect intramolecular interactions to confer changes in eIF4GI structure (Raught et al. 2000a).

\section{eIF4B}

eIF4B was first purified as an activity capable of stimulating translation in a rabbit reticulocyte lysate, and promoting ribosome binding to mRNA in vitro (Benne et al. 1977; Schreier et al. 1977; Benne and Hershey 1978). This ubiquitous protein was later demonstrated to dramatically stimulate the helicase activity of eIF4A (Rozen et al. 1990). eIF4B can dimerize (Methot et al. 1996), and possesses two separate RNA binding domains, an aminoterminal RNA recognition motif (RRM), and a carboxyterminal arginine rich motif (ARM) that binds RNA in a sequence-independent manner (Naranda et al. 1994). eIF4B also displays RNA annealing activity, and has thus been proposed to bridge the mRNA and ribosomal RNA during translation initiation (Altmann et al. 1995). eIF4B appears to play an accessory role in translation; it is not absolutely required for translation in yeast (Altmann et al. 1993) or for initiation complex formation in vitro with mammalian factors (Pestova et al. 1996; Morino et al. 2000). Yeast strains deficient for eIF4B are viable, but display a slow-growth phenotype (Altmann et al. 1993; Coppolecchia et al. 1993). However, eIF4B may play an important role in the discriminatory properties of the general translation machinery: An mRNA with extensive 5'UTR secondary structure is translated poorly in a yeast strain disrupted for eIF4B (Altmann et al. 1993).

Mammalian eIF4B is a phosphoprotein (Benne et al. 1977, 1978; Schreier et al. 1977) and treatment of cells 
with serum, insulin, or phorbol esters results in eIF4B hyperphosphorylation (Duncan and Hershey 1985; Morley and Traugh 1989, 1990). However, the biological significance of eIF4B phosphorylation is unclear. Recombinant eIF4B expressed in E. coli is active both in an in vitro helicase assay (Rozen et al. 1990) and in a ribosome toe-printing assay (Pestova et al. 1996; Morino et al. 2000). eIF4B can be phosphorylated in vitro with several different kinases, including S6K1 (Morley and Traugh 1989, 1990; F. Peiretti and J.W.B. Hershey, pers. comm.). Intriguingly, two-dimensional tryptic phosphopeptide mapping has revealed that eIF4B possesses at least one serum-stimulated phosphorylation site that is sensitive to rapamycin and LY294002 treatment (B. Raught, F. Peiretti, and J.W.B. Hershey, unpubl.). Thus, PI3K and FRAP/mTOR also appear to signal to eIF4B. It remains to be determined whether phosphorylation of eIF4B plays a role in 5'TOP translation.

In summary, how rapamycin exerts its effects on translation initiation is not understood, but the phosphorylation of several translation initiation factors and inhibitors has been clearly demonstrated to lie downstream of PI3K and FRAP/mTOR.

\section{FRAP/mTOR as a sensor molecule}

\section{FRAP/mTOR signals to translation in response to nutrient availability}

In mammals, amino acid levels modulate the activity of several proteins involved in translation, including the 4E-BPs and S6K1 (for review, see Kimball and Jefferson 2000). Amino acid deprivation leads to a reduction in 4E-BP1 and S6K1 phosphorylation (e.g., Hara et al. 1998). Amino acid readdition to amino acid-deprived cells partially restores 4E-BP1 phosphorylation, and synergizes with insulin, IGF-I, or serum to elicit complete phosphorylation (e.g., Hara et al. 1998; Xu et al. 1998a,b). Leucine is critical for 4E-BP1 and S6K1 phosphorylation, and leucine alone (and, to a lesser extent, other branched-chain amino acids) can partially stimulate the phosphorylation of 4E-BP1 and S6K1 in amino acid-deprived cells. The specificity of leucine suggests that a leucine receptor may play an important role in amino acid sensing (for review, see Kimball and Jefferson 2000).

A role for FRAP/mTOR in amino acid signaling was suggested by the observations that a rapamycin-resistant FRAP/mTOR protein confers resistance on S6K1 to amino acid deprivation (Iiboshi et al. 1999), and a rapamycin-resistant S6K1 protein is insensitive to amino acid withdrawal (Hara et al. 1998). Amino acid deprivation does not affect PI3K or Akt/PKB activity, nor does it inhibit the activation of these proteins by serum or insulin treatment (Hara et al. 1998; Patti et al. 1998; Campbell et al. 1999; Kimball et al. 1999; Shigemitsu et al. 1999). Therefore, amino acid modulation of S6K1 and 4E-BP1 phosphorylation does not involve PI3K or Akt/ PKB. Amino acid-induced 4E-BP1 and S6K1 phosphorylation is sensitive to wortmannin treatment (Patti et al. 1998; Wang et al. 1998; Xu et al. 1998a), but at higher concentrations than those required to inhibit phosphorylation of 4E-BP1 and S6K1 after insulin stimulation (Shigemitsu et al. 1999). This is consistent with the concentration of wortmannin required for $\mathrm{FRAP} / \mathrm{mTOR}$ inhibition (Brunn et al. 1996; Sarkaria et al. 1998; see above). Thus, several lines of evidence suggest that FRAP/ mTOR may play an important nutrient checkpoint role, allowing propagation of intracellular signals to the translational apparatus only when sufficient amino acids are present. (Fig. 3)

The connection between Tor and nutrient signaling in yeast has been well documented. Treatment of S. cerevisiae with rapamycin mimics the effects of starvation, and elicits activation or repression of the same subset of genes modulated following a switch from a rich to a poor carbon or nitrogen source (Barbet et al. 1996; Schmidt et al. 1998; Powers and Walter 1999; Beck and Hall 1999; Cardenas et al. 1999; Hardwick et al. 1999; Shamji et al. 2000). Tor also plays an important role in autophagy, and in the regulation of amino acid permeases. The reader is referred to Dennis et al. (1999) and Schmelzle and Hall (2000) for recent reviews.

\section{Is FRAP/mTOR a mediator of "translational homeostasis"?}

Treatment of cells with translational inhibitors such as anisomycin or cycloheximide leads to hyperphosphorylation of both 4E-BP1 and S6K1 (e.g., Brown and Schreiber 1996; von Manteuffel et al. 1996). In contrast, in a murine fibroblast cell line transformed by eIF4E overexpression (Lazaris-Karatzas et al. 1990) in which general translation rates are increased (Rosenwald et al. 1999), both 4E-BP1 and S6K1 are maintained in a hypophosphorylated state (Khaleghpour et al. 1999). Inducible overexpression of eIF4E also leads to 4E-BP1 and S6K1 dephosphorylation, indicating that this effect is due to eIF4E (or increased translation) itself, and is not, in this case, a secondary effect of the transformation process (Khaleghpour et al. 1999). Interestingly, 4E-BP1 was also shown to be hypophosphorylated in several murine mammary tumor cell lines, in contrast to nontumorigenic parental cell strains (Raught et al. 1996). These data are consistent with a model in which the signaling pathways modulating 4E-BP1 and S6K1 activity respond to an unscheduled change in translation initiation. It is also conceivable that transformed cells may acquire the ability to bypass this translational inhibition mechanism.

\section{Regulation of cell growth and proliferation by PI3K and TOR signaling}

In the fruit fly Drosophila melanogaster, the PI3K-Akt/ PKB signaling module plays an important role in the regulation of cell growth (an increase in cell mass) and, in some cases, in the control of proliferation (Leevers et al. 1996; Verdu et al. 1999; Weinkove et al. 1999). Mutations in the PI3K or Akt/PKB Drosophila homologs 
reduce cell size, organ size, and organism size. Ectopic overexpression of these kinases has the opposite effect (Leevers et al. 1996; Verdu et al. 1999; Weinkove et al. 1999). Mutations in dPTEN increase cell growth, whereas overexpression of dPTEN inhibits growth (Goberdhan et al. 1999; Huang et al. 1999; Gao et al. 2000).

Recently, an important role has also been established for the Drosophila FRAP/mTOR ortholog, dTOR, in the regulation of growth and proliferation (Oldham et al. 2000; Zhang et al. 2000). Homozygotic dTOR mutants hatch normally, but larvae grow more slowly and are smaller than their wild type counterparts. These mutants remain viable for as long as 30 days, but eventually die without pupating. Interestingly, dTOR mutant cell clones generated by FLP/FRT-mediated mitotic recombination exhibit a pronounced decrease in cell size in several adult tissues, and in the developing wing imaginal disc (Zhang et al. 2000). Furthermore, the cell cycle phasing of dTOR mutant cell clones differs from control cells, with more cells in $\mathrm{G}_{1}$ and relatively less cells in the $S$ and $G_{2}$ phases (Zhang et al. 2000). This observation is consistent with the ability of rapamycin to arrest yeast and mammalian cells in $\mathrm{G}_{1}$ (Abraham and Wiederrecht 1996; Schmelzle and Hall 2000). Whereas mutations of dPTEN result in increased cell growth, cell clones lacking both dPTEN and dTOR were indistinguishable from dTOR clones, indicating that the growth stimulatory effect of the PI3K pathway requires dTOR function (Zhang et al. 2000).

As is observed in yeast, loss of dTOR function mimics amino acid withdrawal, eliciting an extended larval period accompanied by a reduction in nucleolar area (indicating decreased ribosome biosynthesis; Britton and Edgar 1998; Zhang et al. 2000). In larval endoreplicative tissues (cells which do not divide, but which replicate their DNA complement), loss of dTOR phenocopies the cell cycle arrest elicited by starvation. This cell cycle arrest can be relieved by overexpression of the $\mathrm{G}_{1} / \mathrm{S}$ regulator cyclin E (Zhang et al. 2000). These data provide evidence that dTOR is involved in nutrient sensing, and further suggest that in the presence of sufficient nutrients, dTOR transmits a positive signal, whereas dTOR signaling is inhibited when the amino acid supply is insufficient to support growth.

Phosphorylation of the Drosophila S6K and 4E-BP (a.k.a Thor; Bernal and Kimbrell 2000) orthologs is also sensitive to rapamycin treatment, and thus appears to be downstream of dTOR (Stewart et al. 1996; Miron et al. 2001). Genetic studies have confirmed dS6K as a downstream effector of dTOR, because overexpression of this kinase partially rescues dTOR hypomorphic mutants, allowing them to survive to adulthood (Zhang et al. 2000). This effect is consistent with the phenotype of flies devoid of dS6K (Montagne et al. 1999); although viable, dS6K mutants are significantly smaller than wild-type flies because of a reduction in cell size (Montagne et al. 1999). A decrease in cell size is also observed in cells overexpressing an activated form of Drosophila 4E-BP (Miron et al. 2001).

PI3K and FRAP/mTOR signaling has also been impli- cated in cell growth and proliferation control in mammals. PI3K signaling regulates cell and organ size of the mouse heart (Shioi et al. 2000). As in Drosophila, a FRAP/mTOR mouse mutant (termed flat-top) is significantly smaller than wild-type animals, displays a marked developmental delay, and dies in utero (Hentges et al. 1999; A. Peterson, pers. comm.). Deletion of the murine S6K1 yielded a small mouse phenotype and a growth delay, but knockout mice did not exhibit any other obvious morphological differences from their wildtype counterparts (Shima et al. 1998). Importantly, not all cells are affected to the same degree by S6K1 deletion: For example, a disproportionate decrease in $\beta$-cell size in S6K1-/- mice appears to cause glucose intolerance and hyperinsulinaemia (Pende et al. 2000). This is believed to be caused by the extreme dependence of $\beta$-cells on mitogens and nutrients. The analysis of the results in mice are complicated by the presence of a second S6K isoform (S6K2), which is also rapamycin-sensitive (Shima et al. 1998).

In summary, a plethora of results from yeast, Drosophila, and mice suggest that growth (an increase in mass) and proliferation are points of convergence for at least two distinct sets of cues: signaling from the PI3K pathway, and the presence of sufficient nutrient levels to support growth, as sensed by Tor, dTOR, or FRAP/ mTOR (Fig. 3).

\section{Dysregulation of PI3K and FRAP/mTOR signaling pathways in cell transformation and cancer}

Transforming potential and mutation, amplification, and deletion in tumors

Consistent with the critical importance of PI3K and FRAP/mTOR signaling in the control of growth and proliferation, dysregulation of the activity of several components in this pathway is associated with transformation. For example, PI3K was first discovered as a kinase activity copurifying with the polyoma middle $\mathrm{T}$ antigen and the oncogene v-src (Sugimoto et al. 1984; Whitman et al. 1985). Since these early reports, the transforming ability of several other oncogenes has been demonstrated to correlate with their ability to bind to and activate PI3K (for review, see Cantley et al. 1991). Oncoproteins derived from PI3K itself have also been identified. The p3k protein, isolated from the avian sarcoma virus ASV16 and derived from the catalytic subunit of PI3K, induces hemangiosarcoma in chickens and potently transforms chicken fibroblasts in culture (Chang et al. 1997). p65-PI3K, a truncation mutant of the regulatory PI3K p85 subunit, was isolated from a thymic lymphoma (Jimenez et al. 1998). This protein drives constitutive PI3K activation, causing lymphoproliferative disorders and autoimmunity when expressed in murine $\mathrm{T}$ lymphocytes (Jimenez et al. 1998; Borlado et al. 2000). Overexpression of the PI3K $\alpha$ catalytic subunit, caused by gene amplification, has been detected in $\sim 40 \%$ of ovarian cancers (Shayesteh et al. 1999). Consistent with an increase in PI3K activity as a causal agent, treatment of ovarian 
cancer cells in culture with LY294002 decreased proliferation and increased apoptosis (Shayesteh et al. 1999; $\mathrm{Hu}$ et al. 2000). Furthermore, LY294002 administration decreased the growth of ovarian tumors in athymic mice, and prevented ascites formation (Hu et al. 2000).

One of the most frequent targets for mutation in human cancer is PTEN. PTEN was first identified as a candidate tumor suppressor gene located on chromosome 10 (10q23; Li et al. 1997; Steck et al. 1997). Somatic deletion or homozygous mutation of PTEN is detected in a large proportion of human cancers, and is especially frequent in glioblastomas, melanomas, endometrial carcinomas, and prostate cancers (for review, see Cantley and Neel 1999). Germ-line mutation of PTEN is associated with (1) dominantly inherited syndromes associated with cancer predisposition and (2) developmental defects (e.g., Liaw et al. 1997; Marsh et al. 1997). Ectopic expression of PTEN inhibits the growth of tumor-derived cell lines (for review, see Cantley and Neel 1999|. Disruption of a single copy of PTEN (+/-) in mice induces multiple types of tumors, confirming PTEN as a tumor suppressor, whereas homozygous PTEN null mice die in utero (Di Cristofano et al. 1998; Suzuki et al. 1998; Podsypanina et al. 1999). The basal activity of Akt/PKB is elevated in PTEN-deficient tumor cell lines (as well as in fibroblasts and tumors from PTEN knockout mice), consistent with a resistance of PTEN-/- fibroblasts to apoptosis (for review, see Cantley and Neel 1999).

Akt/PKB was first described as the cellular counterpart of the oncogene $\mathrm{V}$-akt, a protein consisting of an aminoterminal fusion of a viral Gag protein to the amino terminus of Akt, inducing constitutive membrane targeting of the protein (Bellacosa et al. 1991). Overexpression of Akt transforms mammalian cells in culture (e.g., Cheng et al. 1997; Mirza et al. 2000), and Akt/PKB genes are amplified or overexpressed in several cancers (breast, gastric, ovarian, pancreatic, and prostate cancers; Cheng et al. 1992, 1996; Bellacosa et al. 1995; Ruggeri et al. 1998; Nakatani et al. 1999). Overexpression of antisense Akt/PKB mRNA can inhibit tumorigenicity in a pancreatic cell line expressing high Akt/PKB levels /Cheng et al. 1996).

\section{Rapamycin as an anticancer drug}

Although no mutations in FRAP/mTOR have been detected in tumors to date, signaling through FRAP/mTOR appears to be critical for tumor growth. Interestingly, CCI-779 (a rapamycin ester formulated for intravenous use) inhibits the growth in mice of human tumor xenografts deficient in PTEN (C.L. Sawyers, pers. comm.). Lower doses of CCI-779 are required to inhibit PTEN-/tumor growth than PTEN +/+ tumors, indicating that PTEN deletion sensitizes cells to growth arrest elicited by FRAP/mTOR inhibition. This effect is not confined to PTEN deletion, as tumors overexpressing myr-Akt (a membrane-targeted, activated allele of Akt/PKB) are also sensitized to CCI-779 (C.L. Sawyers, pers. comm.). CCI779 administered alone results in growth inhibition (but not the shrinkage of an existing tumor), but CCI-779 treatment combined with androgen withdrawal led to tumor regression in an androgen-dependent prostate cancer xenograft lacking PTEN (C.L. Sawyers, pers. comm.). Rapamycin at low doses $(1 \mathrm{ng} / \mathrm{mL})$ reverses the transformation of chicken embryo fibroblasts expressing p3k or Akt (Aoki et al. 2001). CCI-779 also arrests the growth of various human tumor cells in vivo with different potencies $\left(\mathrm{IC}_{50}\right.$ of $\sim 1 \mathrm{nM}$ to $>1 \mu \mathrm{M}$; Gibbons et al. 1999). In nude mouse xenografts, CCI-779 (when given for five consecutive days) inhibited glioblastoma tumor growth for up to two weeks after drug withdrawal, whereas normal immune function was restored as early as one day following withdrawal, indicating that an intermittent dosage of CCI-779 could be effective (Gibbons et al. 1999). Thus, rapamycin (or its analogs) may be a promising therapeutic agent for the treatment of cancers resulting from a dysregulation of the PI3K pathway.

Excessive growth of Epstein-Barr virus (EBV)-transformed B lymphocytes is often the cause of life-threatening posttransplant lymphoproliferative disorders. Another rapamycin analog, SDZ RAD, which is in use to prevent graft rejection, has an antiproliferative effect on EBV-transformed B lymphocytes in culture and in a mouse model, blocking these cells in $\mathrm{G}_{1}$ and inducing apoptosis (Majewski et al. 2000). Thus, rapamycin analogs may also be useful in the prevention of lymphoid hyperplasia or lymphoma in transplant patients.

In regard to the use of rapamycin either as an immunosuppressant or as an anti-cancer drug, it is important to note that it does not inhibit, but actually stimulates, the translation of mRNAs containing an Internal Ribosome Entry Site (IRES ; for review, see Jackson 2000). All picornaviruses (including poliovirus, rhinovirus, and coxsackieviruses) and the hepatitis $\mathrm{C}$ virus possess an IRES (for review, see Belsham and Jackson 2000), and replication of poliovirus in cultured cells is enhanced by rapamycin (Beretta et al. 1996b; Svitkin et al. 1998). Because some of these viruses establish persistent infections, rapamycin treatment could activate their translation in patients. It will thus be important to assess the risks of this possible side-effect.

\section{Translational targets and cancer}

Overexpression of 4E-BP1 or 4E-BP2 in cells transformed by eIF4E, Src or Ras reverts the transformed phenotype (Rousseau et al. 1996). In the case of Ras-transformed cells, the mechanism appears to be mediated (at least in part) through reversal of the anti-apoptotic activity of Ras (Polunovsky et al. 2000). In fact, 4E-BP1 overexpression sensitizes Ras-transformed cells to apoptosis induced by lovastatin or camptothecin, but does not sensitize the parental cells to apoptosis (Polunovsky et al. 2000). This phenotype is dependent on the ability of 4EBP1 to bind to eIF4E, as a mutant deficient for binding does not lead to apoptosis sensitization (Polunovsky et al. 2000). Similar findings using 4E-BP1 peptides were reported by Herbert et al. (2000).

A significant portion of the anti-tumor effects of rapamycin could be attributable to translational modulation. 
As mentioned previously, eIF4E or eIF4G overexpression results in malignant transformation (Lazaris-Karatzas et al. 1990; Fukuchi-Shimogori et al. 1997). Elevated levels of eIF4F components have been detected in a variety of tumors. For example, a large number of tumors have been found to harbor increased levels of eIF4E (e.g., breast carcinoma, primary bladder cancer, nonHodgkin's lymphoma, and head and neck squamous cell carcinomas; for review, see De Benedetti and Harris 1999; Hershey and Miyamoto 2000). Amplification of the eIF4GI gene has been detected in $30 \%$ of squamous lung carcinomas (Brass et al. 1997). High levels of eIF4AI are found in human melanoma cells (Eberle et al. 1997). Overexpression of various eIF3 subunits in a broad spectrum of cancers was also reported (for review, see Hershey and Miyamoto 2000). Further studies examining the protein levels and activity of the translation initiation factors will be necessary to better define the involvement of these factors in tumor formation.

\section{Conclusions}

A profusion of recent data suggests that FRAP/mTOR acts as a nutrient-sensor checkpoint control protein. In the presence of sufficient nutrients, FRAP/mTOR signals to several translation factors, and specifically enhances the translation of mRNAs involved in growth and proliferation control. This mechanism may explain why inhibition of FRAP/mTOR activity can block tumor growth.

The Tor (and likely FRAP/mTOR) proteins coordinate catabolism versus anabolism. Tor (FRAP/mTOR) not only modulates phosphorylation of translation factors, but also regulates the rate of synthesis of the components of the translation machinery, both at the transcriptional and translational levels (e.g., Cardenas et al. 1999; Hardwick et al. 1999; Powers and Walter 1999). Aside from their effects on translation, these proteins also modulate autophagy and amino acid import (through modulation of permease activity), and regulate the transcription of several enzymes involved in the nitrogen discrimination and glucose activation pathways (in the presence of rapamycin, several of these genes are transcriptionally activated; for review, see Dennis et al. 1999; Schmelzle and Hall 2000). Although only cytoplasmic factors have been implicated in these signaling processes to date, the recent demonstration that FRAP/ mTOR is a nucleocytoplasmic shuttling protein suggests that it could also have direct targets in the nucleus (Kim and Chen 2000).

It is hoped that future research on FRAP/mTOR signaling and its control of translation will increase our understanding of cell growth and proliferation. This research should provide valuable information on the pharmaceutical applications of rapamycin, and other potential inhibitors of this pathway.

\section{Acknowledgments}

We thank M. Miron, F. Peiretti, J.W.B. Hershey, K. Hentges, A.S. Peterson, and C.L. Sawyers for sharing unpublished results and
M.N. Hall, G.J. Belsham, C.L. Sawyers, F. Poulin, M. Miron, and the anonymous reviewers for critical comments. Work in the investigator's laboratory was supported by grants from the Canadian Institutes of Health Research (CIHR), the National Cancer Institute of Canada (NCI), the Howard Hughes Medical Institute (HHMI), and the Human Frontier Science Program (HSFP). A.-C.G. is a recipient of a Medical Research Council of Canada (MRC) doctoral award; B.R. is a recipient of an MRC of Canada post-doctoral fellowship. N.S. is an MRC of Canada Distinguished Scientist and a HHMI International Scholar.

\section{References}

Abraham, R.T. and Wiederrecht, G.J. 1996. Immunopharmacology of rapamycin. Annu. Rev. Immunol. 14: 483-510.

Alarcon, C.M., Heitman, J., and Cardenas, M.E. 1999. Protein kinase activity and identification of a toxic effector domain of the target of rapamycin TOR proteins in yeast. Mol. Biol. Cell 10: 2531-2546.

Altmann, M., Muller, P.P., Wittmer, B., Ruchti, F., Lanker, S., and Trachsel, H. 1993. A Saccharomyces cerevisiae homologue of mammalian translation initiation factor 4B contributes to RNA helicase activity. EMBO J. 12: 3997-4003.

Altmann, M., Wittmer, B., Méthot, N., Sonenberg, N., and Trachsel, H. 1995. The Saccharomyces cerevisiae translation initiation factor Tif3 and its mammalian homologue, eIF-4B, have RNA annealing activity. EMBO I. 14:38203827.

Andrade, M.A. and Bork, P. 1995. HEAT repeats in the Huntington's disease protein. Nat. Genet. 11: 115-116.

Aoki, M., Blazek, E., and Vogt, P.K. 2001. A role of the kinase mTOR in cellular transformation induced by the oncoproteins P3k and Akt. Proc. Natl. Acad. Sci. 98: 136-141.

Barbet, N.C., Schneider, U., Helliwell, S.B., Stansfield, I., Tuite, M.F., and Hall, M.N. 1996. TOR controls translation initiation and early $\mathrm{G}_{1}$ progression in yeast. Mol. Biol. Cell 7: 2542.

Beck, T. and Hall, M.N. 1999. The TOR signalling pathway controls nuclear localization of nutrient-regulated transcription factors. Nature 402: 689-692.

Bellacosa, A., Testa, J.R., Staal, S.P., and Tsichlis, P.N. 1991. A retroviral oncogene, akt, encoding a serine-threonine kinase containing an SH2-like region. Science 254: 274-277.

Bellacosa, A., de Feo, D., Godwin, A.K., Bell, D.W., Cheng, J.Q., Altomare, D.A., Wan, M., Dubeau, L., Scambia, G., Masciullo, V., et al. 1995. Molecular alterations of the AKT2 oncogene in ovarian and breast carcinomas. Int. I. Cancer 64: 280-285.

Belsham, G.J. and Jackson, R.J. 2000. Translation initiation on picornavirus RNA. In Translational control of gene expression (ed. N. Sonenberg, J.W.B. Hershey, and M.B. Mathews), pp. 869-900. Cold Spring Harbor Laboratory Press, Cold Spring Harbor, NY.

Benne, R. and Hershey, J.W.B. 1978. The mechanism of action of protein synthesis initiation factors from rabbit reticulocytes. J. Biol. Chem. 253: 3078-3087.

Benne, R., Luedi, M., and Hershey, J.W.B. 1977. Purification and characterization of initiation factors IF-E4 and IF-E6 from rabbit reticulocytes. J. Biol. Chem. 252: 5798-5803.

Benne, R., Edman, J., Traut, R.R., and Hershey, J.W.B. 1978. Phosphorylation of eukaryotic protein synthesis initiation factors. Proc. Nat1. Acad. Sci. 75: 108-112.

Beretta, L., Gingras, A.-C., Svitkin, Y.V., Hall, M.N., and Sonenberg, N. 1996a. Rapamycin blocks the phosphorylation of 4E-BP1 and inhibits cap-dependent initiation of translation. EMBO I. 15: 658-664. 
Beretta, L., Svitkin, Y.V., and Sonenberg, N. 1996b. Rapamycin stimulates viral protein synthesis and augments the shutoff of host protein synthesis upon picornavirus infection. J. Virol. 70: 8993-8996.

Bernal, A. and Kimbrell, D.A. 2000. Drosophila Thor participates in host immune defense and connects a translational regulator with innate immunity. Proc. Natl. Acad. Sci. 97: 6019-6024.

Borlado, L.R., Redondo, C., Alvarez, B., Jimenez, C., Criado, L.M., Flores, J., Marcos, M.A., Martinez-Aria, C., Balomenos, D., and Carrera, A.C. 2000. Increased phosphoinositide 3-kinase activity induces a lymphoproliferative disorder and contributes to tumor generation in vivo. FASEB I. 14: 895903.

Bosotti, R., Isacchi, A., and Sonnhammer, E.L. 2000. FAT: A novel domain in PIK-related kinases. Trends Biochem. Sci. 25: 225-227.

Bradley, D. 1999. FDA approves new immunosuppressants. Pharmaceutical Sci. Tech. Today 2: 472.

Brass, N., Heckel, D., Sahin, U., Pfreundschuh, M., Sybrecht, G.W., and Meese, E. 1997. Translation initiation factor eIF4gamma is encoded by an amplified gene and induces an immune response in squamous cell lung carcinoma. Hum. Mol. Genet. 6: 33-39.

Britton, J.S. and Edgar, B.A. 1998. Environmental control of the cell cycle in Drosophila: Nutrition activates mitotic and endoreplicative cells by distinct mechanisms. Development 125: 2149-2158.

Brown, E.J. and Schreiber, S.L. 1996. A signaling pathway to translational control. Cell 86: 517-520.

Brown, E.J., Albers, M.W., Shin, T.B., Ichikawa, K., Keith, C.T., Lane, W.S., and Schreiber, S.L. 1994. A mammalian protein targeted by G1-arresting rapamycin-receptor complex. $\mathrm{Na}$ ture 369: 756-758.

Brown, E.J., Beal, P.A., Keith, C.T., Chen, J., Shin, T.B., and Schreiber, S.L. 1995. Control of p70 s6 kinase by kinase activity of FRAP in vivo. Nature 377: 441-446.

Brunn, G.J., Williams, J., Sabers, C., Wiederrecht, G., Lawrence, Jr., J.C., and Abraham, R.T. 1996. Direct inhibition of the signaling functions of the mammalian target of rapamycin by the phosphoinositide 3-kinase inhibitors, wortmannin and LY294002. EMBO J. 15: 5256-5267.

Brunn, G.J., Fadden, P., Haystead, T.A.J., and Lawrence, Jr., J.C. 1997a. The mammalian target of rapamycin phosphorylates sites having a (Ser/Thr)-Pro motif and is activated by antibodies to a region near its $\mathrm{COOH}$ terminus. J. Biol. Chem. 272: 32547-32550.

Brunn, G.J., Hudson, C.C., Sekulic, A., Williams, J.M., Hosoi, H., Houghton, P.J., Lawrence, Jr., J.C., and Abraham, R.T. 1997b. Phosphorylation of the translational repressor PHAS-I by the mammalian target of rapamycin. Science 277: 99-101.

Burnett, P.E., Barrow, R.K., Cohen, N.A., Snyder, S.H., and Sabatini, D.M. 1998. RAFT1 phosphorylation of the translational regulators p70 S6 kinase and 4E-BP1. Proc. Nat1. Acad. Sci. 95: 1432-1437.

Cafferkey, R., Young, P.R., McLaughlin, M.M., Bergsma, D.J., Koltin, Y., Sathe, G.M., Faucette, L., Eng, W.K., Johnson, R.K., and Livi, G.P. 1993. Dominant missense mutations in a novel yeast protein related to mammalian phosphatidylinositol 3-kinase and VPS34 abrogate rapamycin cytotoxicity. Mol. Cell. Biol. 13: 6012-6023.

Cafferkey, R., McLaughlin, M.M., Young, P.R., Johnson, R.K., and Livi, G.P. 1994. Yeast TOR (DRR) proteins: Amino-acid sequence alignment and identification of structural motifs. Gene 141: 133-136.
Campbell, L.E., Wang, X., and Proud, C.G. 1999. Nutrients differentially regulate multiple translation factors and their control by insulin. Biochem. J. 344: 433-441.

Cantley, L.C. and Neel, B.G. 1999. New insights into tumor suppression: PTEN suppresses tumor formation by restraining the phosphoinositide 3-kinase/AKT pathway. Proc. Nat1. Acad. Sci. 96: 4240-4245.

Cantley, L.C., Auger, K.R., Carpenter, C., Duckworth, B., Graziani, A., Kapeller, R., and Soltoff, S. 1991. Oncogenes and signal transduction. Cell 64: 281-302.

Cardenas, M.E., Cutler, N.S., Lorenz, M.C., Di Como, C.J., and Heitman, J. 1999. The TOR signaling cascade regulates gene expression in response to nutrients. Genes \& Dev. 13: 32713279.

Carter, M.S., Kuhn, K.M., and Sarnow, P. 2000. Cellular internal ribosome entry site elements and the use of cDNA microarrays in their investigation. In Translational control of gene expression (ed. N. Sonenberg, J.W.B. Hershey, and M.B. Mathews), pp. 615-635. Cold Spring Harbor Laboratory Press, Cold Spring Harbor, NY.

Casadio, A., Martin, K.C., Giustetto, M., Zhu, H., Chen, M., Bartsch, D., Bailey, C.H., and Kandel, E.R. 1999. A transient, neuron-wide form of CREB-mediated long-term facilitation can be stabilized at specific synapses by local protein synthesis. Cell 99: 221-237.

Chan, T.O., Rittenhouse, S.E., and Tsichlis, P.N. 1999. AKT/ PKB and other D3 phosphoinositide-regulated kinases: Kinase activation by phosphoinositide-dependent phosphorylation. Annu. Rev. Biochem. 68: 965-1014.

Chang, H.W., Aoki, M., Fruman, D., Auger, K.R., Bellacosa, A., Tsichlis, P.N., Cantley, L.C., Roberts, T.M., and Vogt, P.K. 1997. Transformation of chicken cells by the gene encoding the catalytic subunit of PI 3-kinase. Science 276: 1848-1850.

Chen, Y., Chen, H., Rhoad, A.E., Warner, L., Caggiano, T.J., Failli, A., Zhang, H., Hsiao, C.L., Nakanishi, K., and MolnarKimber, K.L. 1994. A putative sirolimus (rapamycin) effector protein. Biochem. Biophys. Res. Commun. 203: 1-7.

Chen, J., Peterson, R.T., and Schreiber, S.L. 1998. Alpha 4 associates with protein phosphatases $2 \mathrm{~A}, 4$, and 6. Biochem. Biophys. Res. Commun. 247: 827-832.

Cheng, J.Q., Godwin, A.K., Bellacosa, A., Taguchi, T., Franke, T.F., Hamilton, T.C., Tsichlis, P.N., and Testa, J.R. 1992. AKT2, a putative oncogene encoding a member of a subfamily of protein-serine/threonine kinases, is amplified in human ovarian carcinomas. Proc. Natl. Acad. Sci. 89: 92679271.

Cheng, J.Q., Ruggeri, B., Klein, W.M., Sonoda, G., Altomare, D.A., Watson, D.K., and Testa, J.R. 1996. Amplification of AKT2 in human pancreatic cells and inhibition of AKT2 expression and tumorigenicity by antisense RNA. Proc. Nat1. Acad. Sci. 93: 3636-3641.

Cheng, J.Q., Altomare, D.A., Klein, M.A., Lee, W.C., Kruh, G.D., Lissy, N.A., and Testa, J.R. 1997. Transforming activity and mitosis-related expression of the AKT2 oncogene: Evidence suggesting a link between cell cycle regulation and oncogenesis. Oncogene 14: 2793-2801.

Chiu, M.I., Katz, H., and Berlin, V. 1994. RAPT1, a mammalian homolog of yeast Tor, interacts with the FKBP12/rapamycin complex. Proc. Natl. Acad. Sci. 91: 12574-12578.

Choi, J., Chen, J., Schreiber, S.L., and Clardy, J. 1996. Structure of the FKBP12-rapamycin complex interacting with the binding domain of human FRAP. Science 273: 239-242.

Chook, Y.M. and Blobel, G. 1999. Structure of the nuclear transport complex karyopherin-beta2-Ran x GppNHp. Nature 399: 230-237.

Cingolani, G., Petosa, C., Weis, K., and Muller, C.W. 1999. 
Structure of importin- $\beta$ bound to the IBB domain of importin- $\alpha$. Nature 399: 221-229.

Coppolecchia, R., Buser, P., Stotz, A., and Linder, P. 1993. A new yeast translation initiation factor suppresses a mutation in the eIF-4A RNA helicase. EMBO J. 12: 4005-4011.

Danaie, P., Altmann, M., Hall, M.N., Trachsel, H., and Helliwell, S.B. 1999. CLN3 expression is sufficient to restore G1to-S-phase progression in Saccharomyces cerevisiae mutants defective in translation initiation factor eIF4E. Biochem. J. 340: 135-141.

De Benedetti, A. and Harris, A. 1999. eIF4E expression in tumours. Int. J. Biochem. Cell Biol. 31: 59-72.

Dennis, P.B., Pullen, N., Kozma, S.C., and Thomas, G. 1996. The principal rapamycin-sensitive $\mathrm{p} 70(\mathrm{~s} 6 \mathrm{k})$ phosphorylation sites, T-229 and T-389, are differentially regulated by rapamycin-insensitive kinase kinases. Mol. Cell. Biol. 16: 62426251.

Dennis, P.B., Fumagalli, S., and Thomas, G. 1999. Target of rapamycin (TOR): Balancing the opposing forces of protein synthesis and degradation. Curr. Opin. Genet. Dev. 9: 49-54.

Di Como, C.J. and Arndt, K.T. 1996. Nutrients, via the Tor proteins, stimulate the association of Tap42 with type $2 \mathrm{~A}$ phosphatases. Genes \& Dev. 10: 1904-1916.

Di Cristofano, A. and Pandolfi, P.P. 2000. The multiple roles of PTEN in tumor suppression. Cell 100: 387-390.

Di Cristofano, A., Pesce, B., Cordon-Cardo, C., and Pandolfi, P.P. 1998. Pten is essential for embryonic development and tumour suppression. Nat. Genet. 19: 348-355.

Dolinski, K., Muir, S., Cardenas, M., and Heitman, J. 1997. All cyclophilins and FK506 binding proteins are, individually and collectively, dispensable for viability in Saccharomyces cerevisiae. Proc. Natl. Acad. Sci. 94: 13093-13098.

Dufner, A., Andjelkovic, M., Burgering, B.M., Hemmings, B.A., and Thomas, G. 1999. Protein kinase B localization and activation differentially affect $\mathrm{S} 6$ kinase 1 activity and eukaryotic translation initiation factor 4E-binding protein 1 phosphorylation. Mol. Cell. Biol. 19: 4525-4534.

Duncan, R. and Hershey, J.W. 1985. Regulation of initiation factors during translational repression caused by serum depletion. Covalent modification. J. Biol. Chem. 260: 5493 5497.

Eberle, J., Krasagakis, K., and Orfanos, C.E. 1997. Translation initiation factor eIF-4Al mRNA is consistently overexpressed in human melanoma cells in vitro. Int. J. Cancer 71: 396-401.

Fadden, P., Haystead, T.A., and Lawrence, Jr., J.C. 1997. Identification of phosphorylation sites in the translational regulator, PHAS-I, that are controlled by insulin and rapamycin in rat adipocytes. J. Biol. Chem. 272: 10240-10247.

Fruman, D.A., Meyers, R.E., and Cantley, L.C. 1998. Phosphoinositide kinases. Annu. Rev. Biochem. 67: 481-507.

Fukuchi-Shimogori, T., Ishii, I., Kashiwagi, K., Mashiba, H., Ekimoto, H., and Igarashi, K. 1997. Malignant transformation by overproduction of translation initiation factor eIF4G. Cancer Res. 57: 5041-5044.

Fumagalli, S. and Thomas, G. 2000. S6 phosphorylation and signal transduction. In Translational control of gene expression (ed. N. Sonenberg, J.W.B. Hershey, and M.B. Mathews), pp. 695-718. Cold Spring Harbor Laboratory Press, Cold Spring Harbor, NY.

Gallego, C., Gari, E., Colomina, N., Herrero, E., and Aldea, M. 1997. The Cln3 cyclin is down-regulated by translational repression and degradation during the G1 arrest caused by nitrogen deprivation in budding yeast. EMBO J. 16: 7196-7206.

Gao, X., Neufeld, T.P., and Pan, D. 2000. Drosophila PTEN regulates cell growth and proliferation through PI3K-depen- dent and -independent pathways. Dev. Biol. 221: 404-418.

Gibbons, J.J., Discafani, C., Peterson, R., Hernandez, R., Skotnicki, J., and Frost, P. 1999. The effect of CCI-779, a novel macrolide anti-tumor agent, on the growth of human tumor cells in vitro and in nude mouse xenografts in vivo. Proc. Amer. Assoc. Cancer Res. 40: 301.

Gingras, A.-C. and Sonenberg, N. 1997. Adenovirus infection inactivates the translational inhibitors 4E-BP1 and 4E-BP2. Virology 237: 182-186.

Gingras, A.-C., Kennedy, S.G., O'Leary, M.A., Sonenberg, N., and Hay, N. 1998. 4E-BP1, a repressor of mRNA translation, is phosphorylated and inactivated by the Akt $(\mathrm{PKB})$ signaling pathway. Genes \& Dev. 12: 502-513.

Gingras, A.-C., Gygi, S.P., Raught, B., Polakiewicz, R.D., Abraham, R.T., Hoekstra, M.F., Aebersold, R., and Sonenberg, N. 1999a. Regulation of 4E-BP1 phosphorylation: A novel twostep mechanism. Genes \& Dev. 13: 1422-1437.

Gingras, A.-C., Raught, B., and Sonenberg, N. 1999b. eIF4 initiation factors: Effectors of mRNA recruitment to ribosomes and regulators of translation. Annu. Rev. Biochem. 68: 913963.

Goberdhan, D.C., Paricio, N., Goodman, E.C., Mlodzik, M., and Wilson, C. 1999. Drosophila tumor suppressor PTEN controls cell size and number by antagonizing the Chico/PI3kinase signaling pathway. Genes \& Dev. 13: 3244-3258.

Gothel, S.F. and Marahiel, M.A. 1999. Peptidyl-prolyl cis-trans isomerases, a superfamily of ubiquitous folding catalysts. Cell. Mol. Life Sci. 55: 423-436.

Groves, M.R. and Barford, D. 1999. Topological characteristics of helical repeat proteins. Curr. Opin. Struct. Biol. 9: 383389.

Groves, M.R., Hanlon, N., Turowski, P., Hemmings, B.A., and Barford, D. 1999. The structure of the protein phosphatase 2A PR65/A subunit reveals the conformation of its 15 tandemly repeated HEAT motifs. Cell 96: 99-110.

Hara, K., Yonezawa, K., Kozlowski, M.T., Sugimoto, T., Andrabi, K., Weng, Q.P., Kasuga, M., Nishimoto, I., and Avruch, J. 1997. Regulation of eIF-4E BP1 phosphorylation by mTOR. J. Biol. Chem. 272: 26457-26463.

Hara, K., Yonezawa, K., Weng, Q.P., Kozlowski, M.T., Belham, C., and Avruch, J. 1998. Amino acid sufficiency and mTOR regulate p70 S6 kinase and eIF-4E BP1 through a common effector mechanism. J. Biol. Chem. 273: 14484-14494.

Harding, M.W., Galat, A., Uehling, D.E., and Schreiber, S.L. 1989. A receptor for the immunosuppressant FK506 is a cistrans peptidyl-prolyl isomerase. Nature 341: 758-760.

Hardwick, J.S., Kuruvilla, F.G., Tong, J.K., Shamji, A.F., and Schreiber, S.L. 1999. Rapamycin-modulated transcription defines the subset of nutrient-sensitive signaling pathways directly controlled by the Tor proteins. Proc. Natl. Acad. Sci. 96: $14866-14870$.

Hartley, K.O., Gell, D., Smith, G.C., Zhang, H., Divecha, N., Connelly, M.A., Admon, A., Lees-Miller, S.P., Anderson, C.W., and Jackson, S.P. 1995. DNA-dependent protein kinase catalytic subunit: A relative of phosphatidylinositol 3-kinase and the ataxia telangiectasia gene product. Cell 82: 849-856.

Heesom, K.J. and Denton, R.M. 1999. Dissociation of the eukaryotic initiation factor-4E/4E-BP1 complex involves phosphorylation of 4E-BP1 by an mTOR-associated kinase. FEBS Lett. 457: 489-493.

Heesom, K.J., Avison, M.B., Diggle, T.A., and Denton, R.M. 1998. Insulin-stimulated kinase from rat fat cells that phosphorylates initiation factor- $4 \mathrm{E}$ binding protein 1 on the rapamycin-insensitive site (serine-111). Biochem. J. 336: 39-48.

Heitman, J., Movva, N.R., and Hall, M.N. 1991a. Targets for cell 
cycle arrest by the immunosuppressant rapamycin in yeast. Science 253: 905-909.

Heitman, J., Movva, N.R., Hiestand, P.C., and Hall, M.N. $1991 \mathrm{~b}$. FK 506-binding protein proline rotamase is a target for the immunosuppressive agent FK 506 in Saccharomyces cerevisiae. Proc. Natl. Acad. Sci. 88: 1948-1952.

Helliwell, S.B., Wagner, P., Kunz, J., Deuter-Reinhard, M., Henriquez, R., and Hall, M.N. 1994. TOR1 and TOR2 are structurally and functionally similar but not identical phosphatidylinositol kinase homologues in yeast. Mol. Biol. Cell 5: $105-118$.

Hentges, K., Thompson, K., and Peterson, A. 1999. The flat-top gene is required for the expansion and regionalization of the telencephalic primordium. Development 126: 1601-1609.

Hentze, M.W. 1997. eIF4G: A multipurpose ribosome adapter? Science 275: 500-501.

Herbert, T.P., Fåhraeus, R., Prescott, A., Lane, D.P., and Proud, C.G. 2000. Rapid induction of apoptosis mediated by peptides that bind initiation factor eIF4E. Curr. Biol. 10: 793796.

Hershey, J.W.B. and Merrick, W.C. 2000. Pathway and mechanism of initiation of protein synthesis. In Translational control of gene expression (ed. N. Sonenberg, J.W.B. Hershey, and M.B. Mathews), pp. 33-88. Cold Spring Harbor Laboratory Press, Cold Spring Harbor, NY.

Hershey, J.W.B. and Miyamoto, S. 2000. Translational control and cancer. In Translational control of gene expression (ed. N. Sonenberg, J.W.B. Hershey, and M.B. Mathews), pp. 637654. Cold Spring Harbor Laboratory Press, Cold Spring Harbor, NY.

Hu, L., Zaloudek, C., Mills, G.B., Gray, J., and Jaffe, R.B. 2000. In vivo and in vitro ovarian carcinoma growth inhibition by a phosphatidylinositol 3-kinase inhibitor (LY294002). Clin. Cancer Res. 6: 880-886.

Huang, H., Potter, C.J., Tao, W., Li, D.M., Brogiolo, W., Hafen, E., Sun, H., and Xu, T. 1999. PTEN affects cell size, cell proliferation and apoptosis during Drosophila eye development. Development 126: 5365-5372.

Iiboshi, Y., Papst, P.J., Kawasome, H., Hosoi, H., Abraham, R.T., Houghton, P.J., and Terada, N. 1999. Amino acid-dependent control of $\mathrm{p} 70(\mathrm{~s} 6 \mathrm{k})$. Involvement of tRNA aminoacylation in the regulation. J. Biol. Chem. 274: 1092-1099.

Imataka, H. and Sonenberg, N. 1997. Human eukaryotic translation initiation factor 4G (eIF4G) possesses two separate and independent binding sites for eIF4A. Mol. Cell. Biol. 17: 6940-6947.

Inui, S., Kuwahara, K., Mizutani, J., Maeda, K., Kawai, T., Nakayasu, H., and Sakaguchi, N. 1995. Molecular cloning of a cDNA clone encoding a phosphoprotein component related to the Ig receptor-mediated signal transduction. I. Immunol. 154: 2714-2723.

Inui, S., Sanjo, H., Maeda, K., Yamamoto, H., Miyamoto, E., and Sakaguchi, N. 1998. Ig receptor binding protein 1 (alpha4) is associated with a rapamycin-sensitive signal transduction in lymphocytes through direct binding to the catalytic subunit of protein phosphatase 2A. Blood 92: 539-546.

Jackson, R.J. 2000. A comparative view of initiation site selection mechanisms. In Translational control of gene expression (ed. N. Sonenberg, J.W.B. Hershey, and M.B. Mathews), pp. 127-183. Cold Spring Harbor Laboratory Press, Cold Spring Harbor, NY.

Jefferies, H.B. and Thomas, G. 1996. Ribosomal protein S6 phosphorylation and signal transduction. In Translational control (ed. J.W.B. Hershey, M. Mathews, and N. Sonenberg), pp. 389-409. Cold Spring Harbor Laboratory Press, Cold Spring Harbor, New York.
Jefferies, H.B., Reinhard, C., Kozma, S.C., and Thomas, G. 1994 Rapamycin selectively represses translation of the "polypyrimidine tract" mRNA family. Proc. Natl. Acad. Sci. 91: 4441-4445.

Jefferies, H.B., Fumagalli, S., Dennis, P.B., Reinhard, C., Pearson, R.B., and Thomas, G. 1997. Rapamycin suppresses 5'TOP mRNA translation through inhibition of p70s6k. EMBO T. 16: 3693-3704.

Jiang, Y. and Broach, J.R. 1999. Tor proteins and protein phosphatase $2 \mathrm{~A}$ reciprocally regulate Tap42 in controlling cell growth in yeast. EMBO J. 18: 2782-2792.

Jimenez, C., Jones, D.R., Rodriguez-Viciana, P., Gonzalez-Garcia, A., Leonardo, E., Wennstrom, S., von Kobbe, C., Toran, J.L., Borlado, L.R., Calvo, V., et al. 1998. Identification and characterization of a new oncogene derived from the regulatory subunit of phosphoinositide 3-kinase. EMBO J. 17: 743753.

Johannes, G., Carter, M.S., Eisen, M.B., Brown, P.O., and Sarnow P. 1999. Identification of eukaryotic mRNAs that are translated at reduced cap binding complex eIF4F concentrations using a cDNA microarray. Proc. Natl. Acad. Sci. 96: $13118-13123$.

Kahan, B.D. 2000. Efficacy of sirolimus compared with azathioprine for reduction of acute renal allograft rejection: A randomised multicentre study. The Rapamune US Study Group. Lancet 356: 194-202.

Khaleghpour, K., Pyronnet, S., Gingras, A.-C., and Sonenberg, N. 1999. Translational homeostasis: Eukaryotic translation initiation factor 4E control of 4E-binding protein 1 and p70 S6 kinase activities. Mol. Cell. Biol. 19: 4302-4310.

Kim, J.E. and Chen, J. 2000. Cytoplasmic-nuclear shuttling of FKBP12-rapamycin-associated protein is involved in rapamycin-sensitive signaling and translation initiation. Proc. Natl. Acad. Sci. 97: 14340-14345.

Kimball, S.R. and Jefferson, L.S. 2000. Regulation of translation initiation in mammalian cells by amino acids. In Translational control of gene expression (ed. N. Sonenberg, J.W.B. Hershey, and M.B. Mathews), pp. 561-580. Cold Spring Harbor Laboratory Press, Cold Spring Harbor, New York.

Kimball, S.R., Shantz, L.M., Horetsky, R.L., and Jefferson, L.S. 1999. Leucine regulates translation of specific mRNAs in L6 myoblasts through mTOR-mediated changes in availability of eIF4E and phosphorylation of ribosomal protein S6. J. Biol. Chem. 274: 11647-11652.

Kleijn, M., Scheper, G.C., Voorma, H.O., and Thomas, A.A.M. 1998. Regulation of translation initiation factors by signal transduction. Eur. J. Biochem. 253: 531-544.

Kohn, A.D., Barthel, A., Kovacina, K.S., Boge, A., Wallach, B., Summers, S.A., Birnbaum, M.J., Scott, P.H., Lawrence, Jr., J.C., and Roth, R.A. 1998. Construction and characterization of a conditionally active version of the serine/threonine kinase Akt. J. Biol. Chem. 273: 11937-11943.

Koltin, Y., Faucette, L., Bergsma, D.J., Levy, M.A., Cafferkey, R., Koser, P.L., Johnson, R.K., and Livi, G.P. 1991. Rapamycin sensitivity in Saccharomyces cerevisiae is mediated by a peptidyl-prolyl cis-trans isomerase related to human FK506binding protein. Mol. Cell. Biol. 11: 1718-1723.

Koromilas, A.E., Lazaris-Karatzas, A., and Sonenberg, N. 1992. mRNAs containing extensive secondary structure in their $5^{\prime}$ noncoding region translate efficiently in cells overexpressing initiation factor eIF-4E. EMBO J. 11: 4153-4158.

Kozak, M. 1989. The scanning model for translation: An update. J. Cell Biol. 108: 229-241.

- 1991. An analysis of vertebrate mRNA sequences: Intimations of translational control. J. Cell Biol. 115: 887-903.

Kumar, V., Pandey, P., Sabatini, D., Kumar, M., Majumder, P.K., 
Bharti, A., Carmichael, G., Kufe, D., and Kharbanda, S. 2000a. Functional interaction between RAFT1/FRAP/ mTOR and protein kinase $C$ delta in the regulation of capdependent initiation of translation. EMBO J. 19: 1087-1097.

Kumar, V., Sabatini, D., Pandey, P., Gingras, A.-C., Majumder, P.K., Kumar, M., Yuan, Z.M., Carmichael, G., Weichselbaum, R., Sonenberg, N., et al. 2000b. Regulation of the rapamycin and FKBP-target 1/mammalian target of rapamycin and cap-dependent initiation of translation by the c-Abl protein-tyrosine kinase. J. Biol. Chem. 275: 10779-10787.

Kunz, J., Henriquez, R., Schneider, U., Deuter-Reinhard, M., Movva, N.R., and Hall, M.N. 1993. Target of rapamycin in yeast, TOR2, is an essential phosphatidylinositol kinase homolog required for G1 progression. Cell 73: 585-596.

Kunz, J., Schneider, U., Howald, I., Schmidt, A., and Hall, M.N. 2000. HEAT repeats mediate plasma membrane localization of Tor2p in yeast. J. Biol. Chem. 275: 37011-37020.

Lamphear, B.J., Kirchweger, R., Skern, T., and Rhoads, R.E. 1995. Mapping of functional domains in eukaryotic protein synthesis initiation factor 4G (eIF4G) with picornaviral proteases. Implications for cap-dependent and cap-independent translational initiation. J. Biol. Chem. 270: 21975-21983.

Lazaris-Karatzas, A., Montine, K.S., and Sonenberg, N. 1990. Malignant transformation by a eukaryotic initiation factor subunit that binds to mRNA 5' cap. Nature 345: 544-547.

Leevers, S.J., Weinkove, D., MacDougall, L.K., Hafen, E., and Waterfield, M.D. 1996. The Drosophila phosphoinositide 3-kinase Dp110 promotes cell growth. EMBO J. 15: 65846594.

Li, J., Yen, C., Liaw, D., Podsypanina, K., Bose, S., Wang, S.I., Puc, J., Miliaresis, C., Rodgers, L., McCombie, R., et al. 1997. PTEN, a putative protein tyrosine phosphatase gene mutated in human brain, breast, and prostate cancer. Science 275: 1943-1947.

Liaw, D., Marsh, D.J., Li, J., Dahia, P.L., Wang, S.I., Zheng, Z., Bose, S., Call, K.M., Tsou, H.C., Peacocke, M., et al. 1997. Germline mutations of the PTEN gene in Cowden disease, an inherited breast and thyroid cancer syndrome. Nat. Genet. 16: 64-67.

Lin, T.A. and Lawrence, J.C., Jr. 1996. Control of the translational regulators PHAS-I and PHAS-II by insulin and cAMP in 3T3-L1 adipocytes. J. Biol. Chem. 271: 30199-30204.

Lin, T.A., Kong, X., Haystead, T.A., Pause, A., Belsham, G., Sonenberg, N., and Lawrence, J.C., Jr. 1994. PHAS-I as a link between mitogen-activated protein kinase and translation initiation. Science 266: 653-656.

Lin, T.A., Kong, X., Saltiel, A.R., Blackshear, P.J., and Lawrence, J.C., Jr. 1995. Control of PHAS-I by insulin in 3T3-L1 adipocytes. Synthesis, degradation, and phosphorylation by a rapamycin-sensitive and mitogen-activated protein kinase-independent pathway. J. Biol. Chem. 270: 18531-18538.

Lodish, H.F. 1976. Translational control of protein synthesis. Annu. Rev. Biochem. 45: 39-72.

Lorenz, M.C. and Heitman, J. 1995. TOR mutations confer rapamycin resistance by preventing interaction with FKBP12rapamycin. J. Biol. Chem. 270: 27531-27537.

Mahalingam, M. and Templeton, D. 1996. Constitutive activation of S6 kinase by deletion of amino-terminal autoinhibitory and rapamycin sensitivity domains. Mol. Cell. Biol. 16: 405-413.

Majewski, M., Korecka, M., Kossev, P., Li, S., Goldman, J., Moore, J., Silberstein, L.E., Nowell, P.C., Schuler, W., Shaw, L.M., et al. 2000. The immunosuppressive macrolide RAD inhibits growth of human Epstein-Barr virus-transformed B lymphocytes in vitro and in vivo: A potential approach to prevention and treatment of posttransplant lymphoprolifera- tive disorders. Proc. Natl. Acad. Sci. 97: 4285-4290.

Manzella, J.M., Rychlik, W., Rhoads, R.E., Hershey, J.W., and Blackshear, P.J. 1991. Insulin induction of ornithine decarboxylase. Importance of mRNA secondary structure and phosphorylation of eucaryotic initiation factors eIF-4B and eIF-4E. J. Biol. Chem. 266: 2383-2389.

Marcotrigiano, J., Gingras, A.-C., Sonenberg, N., and Burley, S.K. 1999. Cap-dependent translation initiation in eukaryotes is regulated by a molecular mimic of eIF4G. Mol. Cell 3: 707-716.

Marcotrigiano, J., Lomakin, I.B., Sonenberg, N., Pestova, T.V., Hellen, C.U.T., and Burley, S.K. 2001. A conserved HEAT domain within eIF4G directs assembly of the translation initiation machinery. Mol. Cell 7: 193-203.

Marsh, D.J., Dahia, P.L., Zheng, Z., Liaw, D., Parsons, R., Gorlin, R.J., and Eng, C. 1997. Germline mutations in PTEN are present in Bannayan-Zonana syndrome. Nat. Genet. 16: 333-334.

Mathews, M.B., Sonenberg, N., and Hershey, J.W.B. 2000. Origins and principles of translational control. In Translational control of gene expression (ed. N. Sonenberg, J.W.B. Hershey, and M.B. Mathews), pp. 1-31. Cold Spring Harbor Laboratory Press, Cold Spring Harbor, New York.

Methot, N., Song, M., and Sonenberg, N. 1996. A region rich in aspartic acid, arginine, tyrosine, and glycine (DRYG) mediates eukaryotic initiation factor 4B (eIF4B) self-association and interaction with eIF3. Mol. Cell. Biol. 16: 5328-5334.

Meyuhas, O. and Hornstein, E. 2000. Translational control of TOP mRNAs. In Translational control of gene expression (ed. N. Sonenberg, J.W.B. Hershey, and M.B. Mathews), pp. 671-694. Cold Spring Harbor Laboratory Press, Cold Spring Harbor, New York.

Meyuhas, O., Avni, D., and Shama, S. 1996. Translational control of ribosomal protein mRNAs in eukaryotes. In Translational control (ed. J.W.B. Hershey, M. Mathews, and N. Sonenberg), pp. 363-388. Cold Spring Harbor Laboratory Press, Cold Spring Harbor, NY.

Mikulits, W., Pradet-Balade, B., Habermann, B., Beug, H., Garcia-Sanz, J.A., and Mullner, E.W. 2000. Isolation of translationally controlled mRNAs by differential screening. FASEB J. 14: 1641-1652.

Miron, M., Verdu, J., Lachance, P.E.D., Birnbaum, M.J., Lasko, P.F., and Sonenberg, N. 2001. The translational inhibitor 4E$\mathrm{BP}$ is an effector of PI3K/Akt signaling in Drosophila, and regulates cell growth. Nat. Cell Biol. (in press).

Mirza, A.M., Kohn, A.D., Roth, R.A., and McMahon, M. 2000. Oncogenic transformation of cells by a conditionally active form of the protein kinase Akt/PKB. Cell Growth Differ. 11: 279-292.

Montagne, J., Stewart, M.J., Stocker, H., Hafen, E., Kozma, S.C., and Thomas, G. 1999. Drosophila S6 kinase: A regulator of cell size. Science 285: 2126-2129.

Morino, S., Imataka, H., Svitkin, Y.V., Pestova, T.V., and Sonenberg, N. 2000. Eukaryotic translation initiation factor 4E (eIF4E) binding site and the middle one-third of eIF4GI constitute the core domain for cap-dependent translation, and the C-terminal one-third functions as a modulatory region. Mol. Cell. Biol. 20: 468-477.

Morley, S.J. and Traugh, J.A. 1989. Phorbol esters stimulate phosphorylation of eukaryotic initiation factors 3,4B, and 4F. J. Biol. Chem. 264: 2401-2404.

- 1990. Differential stimulation of phosphorylation of initiation factors eIF-4F, eIF-4B, eIF-3, and ribosomal protein S6 by insulin and phorbol esters. J. Biol. Chem. 265: 1061110616.

Mothe-Satney, I., Brunn, G.J., McMahon, L.P., Capaldo, C.T., 
Abraham, R.T., and Lawrence, J.C., Jr. 2000a. Mammalian Target of Rapamycin-dependent phosphorylation of PHAS-I in Four (S/T)P Sites detected by phospho-specific antibodies. J. Biol. Chem. 275: 33836-33843.

Mothe-Satney, I., Yang, D., Fadden, P., Haystead, T.A., and Lawrence, J.C., Jr. 2000b. Multiple mechanisms control phosphorylation of PHAS-I in five (S/T)P sites that govern translational repression. Mol. Cell. Biol. 20: 3558-3567.

Muise-Helmericks, R.C., Grimes, H.L., Bellacosa, A., Malstrom, S.E., Tsichlis, P.N., and Rosen, N. 1998. Cyclin D expression is controlled post-transcriptionally via a phosphatidylinositol 3-kinase/Akt-dependent pathway. J. Biol. Chem. 273: 29864-29872.

Murata, K., Wu, J., and Brautigan, D.L. 1997. B cell receptorassociated protein alpha4 displays rapamycin-sensitive binding directly to the catalytic subunit of protein phosphatase 2A. Proc. Natl. Acad. Sci. 94: 10624-10629.

Nakatani, K., Thompson, D.A., Barthel, A., Sakaue, H., Liu, W., Weigel, R.J., and Roth, R.A. 1999. Up-regulation of Akt3 in estrogen receptor-deficient breast cancers and androgen-independent prostate cancer lines. J. Biol. Chem. 274: 2152821532.

Nanahoshi, M., Nishiuma, T., Tsujishita, Y., Hara, K., Inui, S., Sakaguchi, N., and Yonezawa, K. 1998. Regulation of protein phosphatase $2 \mathrm{~A}$ catalytic activity by alpha4 protein and its yeast homolog TAP42. Biochem. Biophys. Res. Commun. 251: 52-526.

Nanahoshi, M., Tsujishita, Y., Tokunaga, C., Inui, S., Sakaguchi, N., Hara, K., and Yonezawa, K. 1999. Alpha4 protein as a common regulator of type 2A-related serine/threonine protein phosphatases. FEBS Lett. 446: 108-112.

Naranda, T., Strong, W.B., Menaya, J., Fabbri, B.J., and Hershey, J.W. 1994. Two structural domains of initiation factor eIF-4B are involved in binding to RNA. J. Biol. Chem. 269: 1446514472.

Navé, B.T., Ouwens, M., Withers, D.J., Alessi, D.R., and Shepherd, P.R. 1999. Mammalian target of rapamycin is a direct target for protein kinase B: Identification of a convergence point for opposing effects of insulin and amino-acid deficiency on protein translation. Biochem. J. 344: 427-431.

Nielsen, F.C., Ostergaard, L., Nielsen, J., and Christiansen, J. 1995. Growth-dependent translation of IGF-II mRNA by a rapamycin-sensitive pathway. Nature 377: 358-362.

Nielsen, J., Christiansen, J., Lykke-Andersen, J., Johnsen, A.H., Wewer, U.M., and Nielsen, F.C. 1999. A family of insulinlike growth factor II mRNA-binding proteins represses translation in late development. Mol. Cell. Biol. 19: 1262-1270.

Oldham, S., Montagne, J., Radimerski, T., Thomas, G., and Hafen, E. 2000. Genetic and biochemical characterization of dTOR, the Drosophila homolog of the target of rapamycin. Genes \& Dev. 14: 2689-2694.

Patti, M.E., Brambilla, E., Luzi, L., Landaker, E.J., and Kahn, C.R. 1998. Bidirectional modulation of insulin action by amino acids. J. Clin. Invest. 101: 1519-1529.

Pause, A., Belsham, G.J., Gingras, A.-C., Donzé, O., Lin, T.A., Lawrence, Jr., J.C., and Sonenberg, N. 1994. Insulin-dependent stimulation of protein synthesis by phosphorylation of a regulator of 5'-cap function. Nature 371: 762-767.

Pedersen, S., Celis, J.E., Nielsen, J., Christiansen, J., and Nielsen, F.C. 1997. Distinct repression of translation by wortmannin and rapamycin. Eur. J. Biochem. 247: 449-456.

Pende, M., Kozma, S.C., Jaquet, M., Oorschot, V., Burcelin, R., Le Marchand-Brustel, Y., Klumperman, J., Thorens, B., and Thomas, G. 2000. Hypoinsulinaemia, glucose intolerance and diminished b-cell size in S6K1-deficient mice. Nature 408: 994-997.
Pestova, T.V., Shatsky, I.N., and Hellen, C.U.T. 1996. Functional dissection of eukaryotic initiation factor 4F: The 4A subunit and the central domain of the 4G subunit are sufficient to mediate internal entry of $43 \mathrm{~S}$ preinitiation complexes. Mol. Cell. Biol. 16: 6870-6878.

Peterson, R.T., Desai, B.N., Hardwick, J.S., and Schreiber, S.L. 1999. Protein phosphatase $2 \mathrm{~A}$ interacts with the $70-\mathrm{kDa}$ S6 kinase and is activated by inhibition of FKBP12-rapamycin associated protein. Proc. Natl. Acad. Sci. 96: 4438-4442.

Peterson, R.T., Beal, P.A., Comb, M.J., and Schreiber, S.L. 2000. FKBP12-rapamycin-associated protein (FRAP) autophosphorylates at serine 2481 under translationally repressive conditions. I. Biol. Chem. 275: 7416-7423.

Podsypanina, K., Ellenson, L.H., Nemes, A., Gu, J., Tamura, M., Yamada, K.M., Cordon-Cardo, C., Catoretti, G., Fisher, P.E., and Parsons, R. 1999. Mutation of Pten/Mmac1 in mice causes neoplasia in multiple organ systems. Proc. Nat1. Acad. Sci. 96: 1563-1568.

Polunovsky, V.A., Gingras, A.-C., Sonenberg, N., Peterson, M., Tan, A., Rubins, J.B., Manivel, J.C., and Bitterman, P.B. 2000. Translational control of the antiapoptotic function of Ras. $J$. Biol. Chem. 275: 24776-24780.

Polymenis, M. and Schmidt, E.V. 1997. Coupling of cell division to cell growth by translational control of the $\mathrm{G}_{1}$ cyclin CLN3 in yeast. Genes \& Dev. 11: 2522-2531.

Powers, T. and Walter, P. 1999. Regulation of ribosome biogenesis by the rapamycin-sensitive TOR-signaling pathway in Saccharomyces cerevisiae. Mol. Biol. Cell 10: 987-1000.

Powis, G., Bonjouklian, R., Berggren, M.M., Gallegos, A., Abraham, R., Ashendel, C., Zalkow, L., Matter, W.F., Dodge, J., and Grindey, G. 1994. Wortmannin, a potent and selective inhibitor of phosphatidylinositol-3-kinase. Cancer Res. 54: 2419-2423.

Proud, C.G. 2000. Control of the elongation phase of protein synthesis. In Translational control of gene expression (ed. N. Sonenberg, J.W.B. Hershey, and M.B. Mathews), pp. 719-739. Cold Spring Harbor Laboratory Press, Cold Spring Harbor, New York.

Pullen, N., Dennis, P.B., Andjelkovic, M., Dufner, A., Kozma, S.C., Hemmings, B.A., and Thomas, G. 1998. Phosphorylation and activation of p70s6k by PDK1. Science 279: 707710 .

Pyronnet, S., Gingras, A.-C., Bouisson, M., Kowalski-Chauvel, A., Seva, C., Vaysse, N., Sonenberg, N., and Pradayrol, L. 1998. Gastrin induces phosphorylation of eIF4E binding protein 1 and translation initiation of ornithine decarboxylase mRNA. Oncogene 16: 2219-2227.

Raught, B., Gingras, A.-C., James, A., Medina, D., Sonenberg, N., and Rosen, J.M. 1996. Expression of a translationally regulated, dominant-negative CCAAT/enhancer-binding protein beta isoform and up-regulation of the eukaryotic translation initiation factor 2 alpha are correlated with neoplastic transformation of mammary epithelial cells. Cancer Res. 56: 4382-4386.

Raught, B., Gingras, A.-C., Gygi, S.P., Imataka, H., Morino, S., Gradi, A., Aebersold, R., and Sonenberg, N. 2000a. Serumstimulated, rapamycin-sensitive phosphorylation sites in the eukaryotic translation initiation factor 4GI. EMBO $\mathrm{J}$. 19: 434-444.

Raught, B., Gingras, A.-C., and Sonenberg, N. 2000b. Regulation of ribosomal recruitment in eukaryotes. In Translational control of gene expression (ed. N. Sonenberg, J.W.B. Hershey, and M.B. Mathews), pp. 245-294. Cold Spring Harbor Laboratory Press, Cold Spring Harbor, New York.

Rosenwald, I.B., Chen, J.J., Wang, S., Savas, L., London, I.M., and Pullman, J. 1999. Upregulation of protein synthesis initia- 
tion factor eIF-4E is an early event during colon carcinogenesis. Oncogene 18: 2507-2517.

Rousseau, D., Gingras, A.-C., Pause, A., and Sonenberg, N. 1996. The eIF4E-binding proteins 1 and 2 are negative regulators of cell growth. Oncogene 13: 2415-2420.

Rozen, F., Edery, I., Meerovitch, K., Dever, T.E., Merrick, W.C., and Sonenberg, N. 1990. Bidirectional RNA helicase activity of eucaryotic translation initiation factors $4 \mathrm{~A}$ and $4 \mathrm{~F}$. Mol. Cell. Biol. 10: 1134-1144.

Ruggeri, B.A., Huang, L., Wood, M., Cheng, J.Q., and Testa, J.R. 1998. Amplification and overexpression of the AKT2 oncogene in a subset of human pancreatic ductal adenocarcinomas. Mol. Carcinog. 21: 81-86.

Rybkin, I.I., Cross, M.E., McReynolds, E.M., Lin, R.Z., and Ballou, L.M. 2000. a1A Adrenergic receptor induces eukaryotic initiation factor 4E-binding protein 1 phosphorylation via a $\mathrm{Ca}^{2+}$-dependent pathway independent of phosphatidylinositol 3-kinase/Akt. J. Biol. Chem. 275: 5460-5465.

Sabatini, D.M., Erdjument-Bromage, H., Lui, M., Tempst, P., and Snyder, S.H. 1994. RAFT1: A mammalian protein that binds to FKBP12 in a rapamycin-dependent fashion and is homologous to yeast TORs. Cell 78: 35-43.

Sabatini, D.M., Barrow, R.K., Blackshaw, S., Burnett, P.E., Lai, M.M., Field, M.E., Bahr, B.A., Kirsch, J., Betz, H., and Snyder, S.H. 1999. Interaction of RAFT1 with gephyrin required for rapamycin-sensitive signaling. Science 284: 1161-1164.

Sabers, C.J., Martin, M.M., Brunn, G.J., Williams, J.M., Dumont, F.J., Wiederrecht, G., and Abraham, R.T. 1995. Isolation of a protein target of the FKBP12-rapamycin complex in mammalian cells. J. Biol. Chem. 270: 815-822.

Sarkaria, J.N., Tibbetts, R.S., Busby, E.C., Kennedy, A.P., Hill, D.E., and Abraham, R.T. 1998. Inhibition of phosphoinositide 3-kinase related kinases by the radiosensitizing agent wortmannin. Cancer Res. 58: 4375-4382.

Schmelzle, T. and Hall, M.N. 2000. TOR, a central controller of cell growth. Cell 103: 253-262.

Schmidt, A., Kunz, J., and Hall, M.N. 1996. TOR2 is required for organization of the actin cytoskeleton in yeast. Proc. Natl. Acad. Sci. 93: 13780-13785.

Schmidt, A., Bickle, M., Beck, T., and Hall, M.N. 1997. The yeast phosphatidylinositol kinase homolog TOR2 activates RHO1 and RHO2 via the exchange factor ROM2. Cell 88: $531-542$.

Schmidt, A., Beck, T., Koller, A., Kunz, J., and Hall, M.N. 1998. The Tor nutrient signalling pathway phosphorylates NPR1 and inhibits turnover of the tryptophan permease. EMBO $\mathrm{J}$. 17: 6924-6931.

Schneider, R.J. 2000. Translational control during heat shock. In Translational control of gene expression (ed. N. Sonenberg, J.W.B. Hershey, and M.B. Mathews), pp. 581-593. Cold Spring Harbor Laboratory Press, Cold Spring Harbor, NY.

Schreier, M.H., Erni, B., and Staehelin, T. 1977. Initiation of mammalian protein synthesis. I. Purification and characterization of seven initiation factors. J. Mol. Biol. 116: 727-753.

Schwab, M.S., Kim, S.H., Terada, N., Edfjäll, C., Kozma, S.C., Thomas, G., and Maller, J.L. 1999. p70(S6K) controls selective mRNA translation during oocyte maturation and early embryogenesis in Xenopus laevis. Mol. Cell. Biol. 19: 24852494.

Scott, P.H. and Lawrence, Jr., J.C. 1998. Attenuation of mammalian Target of Rapamycin activity by increased cAMP in 3T3-L1 cells. J. Biol. Chem. 272: 34496-34501.

Scott, P.H., Brunn, G.J., Kohn, A.D., Roth, R.A., and Lawrence, Jr., J.C. 1998. Evidence of insulin-stimulated phosphorylation and activation of the mammalian target of rapamycin mediated by a protein kinase B signaling pathway. Proc.
Nat1. Acad. Sci. 95: 7772-7777.

Seidel, E.R. and Ragan, V.L. 1997. Inhibition by rapamycin of ornithine decarboxylase and epithelial cell proliferation in intestinal IEC-6 cells in culture. Br. J. Pharmacol. 120: 571574.

Sekulic, A., Hudson, C.C., Homme, J.L., Yin, P., Otterness, D.M., Karnitz, L.M., and Abraham, R.T. 2000. A direct linkage between the phosphoinositide 3-kinase-AKT signaling pathway and the mammalian target of rapamycin in mitogen-stimulated and transformed cells. Cancer Res. 60: 3504 3513.

Shamji, A.F., Kuruvilla, F.G., and Schreiber, S.L. 2000. Partitioning the transcriptional program induced by rapamycin among the effectors of the Tor proteins. Curr. Biol. 10: 15741581.

Shantz, L.M., Coleman, C.S., and Pegg, A.E. 1996. Expression of an ornithine decarboxylase dominant-negative mutant reverses eukaryotic initiation factor 4E-induced cell transformation. Cancer Res. 56: 5136-5140.

Shayesteh, L., Lu, Y., Kuo, W.L., Baldocchi, R., Godfrey, T., Collins, C., Pinkel, D., Powell, B., Mills, G.B., and Gray, J.W. 1999. PIK3CA is implicated as an oncogene in ovarian cancer. Nat. Genet. 21: 99-102.

Shigemitsu, K., Tsujishita, Y., Hara, K., Nanahoshi, M., Avruch, J., and Yonezawa, K. 1999. Regulation of translational effectors by amino acid and mammalian target of rapamycin signaling pathways. Possible involvement of autophagy in cultured hepatoma cells. J. Biol. Chem. 274: 1058-1065.

Shima, H., Pende, M., Chen, Y., Fumagalli, S., Thomas, G., and Kozma, S.C. 1998. Disruption of the p70S6k/p85S6k gene reveals a small mouse phenotype and a new functional S6 kinase. EMBO J. 17: 6649-6659.

Shioi, T., Kang, P.M., Douglas, P.S., Hampe, J., Yballe, C.M., Lawitts, J., Cantley, L.C., and Izumo, S. 2000. The conserved phosphoinositide 3-kinase pathway determines heart size in mice. EMBO J. 19: 2537-2548.

Siekierka, J.J., Hung, S.H., Poe, M., Lin, C.S., and Sigal, N.H. 1989. A cytosolic binding protein for the immunosuppressant FK506 has peptidyl-prolyl isomerase activity but is distinct from cyclophilin. Nature 341: 755-757.

Siekierka, J.J., Wiederrecht, G., Greulich, H., Boulton, D., Hung, S.H., Cryan, J., Hodges, P.J., and Sigal, N.H. 1990. The cytosolic-binding protein for the immunosuppressant FK-506 is both a ubiquitous and highly conserved peptidyl-prolyl cistrans isomerase. J. Biol. Chem. 265: 21011-21015.

Sonenberg, N. 1993. Remarks on the mechanism of ribosome binding to eukaryotic mRNAs. Gene. Expr. 3: 317-323.

Sonenberg, N., Hershey, J.W.B., and Mathews, M.B. 2000 Translational control of gene expression. Cold Spring Harbor Laboratory Press, Cold Spring Harbor, New York.

Steck, P.A., Pershouse, M.A., Jasser, S.A., Yung, W.K., Lin, H., Ligon, A.H., Langford, L.A., Baumgard, M.L., Hattier, T., Davis, T., et al. 1997. Identification of a candidate tumour suppressor gene, MMAC1, at chromosome 10q23.3 that is mutated in multiple advanced cancers. Nat. Genet. 15: 356362.

Stewart, M.J., Berry, C.O., Zilberman, F., Thomas, G., and Kozma, S.C. 1996. The Drosophila p70s6k homolog exhibits conserved regulatory elements and rapamycin sensitivity. Proc. Natl. Acad. Sci. 93: 10791-10796.

Sugimoto, Y., Whitman, M., Cantley, L.C., and Erikson, R.L. 1984. Evidence that the Rous sarcoma virus transforming gene product phosphorylates phosphatidylinositol and diacylglycerol. Proc. Nat1. Acad. Sci. 81: 2117-2121.

Suzuki, A., de la Pompa, J.L., Stambolic, V., Elia, A.J., Sasaki, T., del Barco Barrantes, I., Ho, A., Wakeham, A., Itie, A., et al. 
1998. High cancer susceptibility and embryonic lethality associated with mutation of the PTEN tumor suppressor gene in mice. Curr. Biol. 8: 1169-1178.

Svitkin, Y.V., Hahn, H., Gingras, A.-C., Palmenberg, A.C., and Sonenberg, N. 1998. Rapamycin and wortmannin enhance replication of a defective encephalomyocarditis virus. J. Virol. 72: 5811-5819.

Svitkin, Y., Pause, A., Haghighat, A., Pyronnet, S., Witherell, G.W., Belsham, G., and Sonenberg, N. 2001. The requirement for eukaryotic initiation factor 4A (eIF4A) in translation is in direct proportion to the degree of mRNA $5^{\prime}$ secondary structure. RNA (in press).

Taha, C., Liu, Z., Jin, J., Al-Hasani, H., Sonenberg, N., and Klip, A. 1999. Opposite translational control of GLUT1 and GLUT4 glucose transporter mRNAs in response to insulin. Role of mammalian target of rapamycin, protein kinase B, and phosphatidylinositol 3-kinase in GLUT1 mRNA translation. J. Biol. Chem. 274: 33085-33091.

Takata, M., Ogawa, W., Kitamura, T., Hino, Y., Kuroda, S., Kotani, K., Klip, A., Gingras, A.-C., Sonenberg, N., and Kasuga, M. 1999. Requirement for Akt (protein kinase B) in insulininduced activation of glycogen synthase and phosphorylation of 4E-BP1 (PHAS-1). J. Biol. Chem. 274: 20611-20618.

Terada, N., Patel, H.R., Takase, K., Kohno, K., Nairn, A.C., and Gelfand, E.W. 1994. Rapamycin selectively inhibits translation of mRNAs encoding elongation factors and ribosomal proteins. Proc. Natl. Acad. Sci. 91: 11477-11481.

Thomas, G. and Hall, M.N. 1997. TOR signalling and control of cell growth. Curr. Opin. Cell. Biol. 9: 782-787.

Ui, M., Okada, T., Hazeki, K., and Hazeki, O. 1995. Wortmannin as a unique probe for an intracellular signalling protein, phosphoinositide 3-kinase. Trends Biochem. Sci. 20: 303-307.

Verdu, J., Buratovich, M.A., Wilder, E.L., and Birnbaum, M.J. 1999. Cell-autonomous regulation of cell and organ growth in Drosophila by Akt/PKB. Nat. Cell Biol. 1: 500-506.

Vetter, I.R., Arndt, A., Kutay, U., Gorlich, D., and Wittinghofer, A. 1999. Structural view of the Ran-Importin beta interaction at 2.3 A resolution. Cell 97: 635-646.

Vezina, C., Kudelski, A., and Sehgal, S.N. 1975. Rapamycin (AY22,989 ), a new antifungal antibiotic. I. Taxonomy of the producing streptomycete and isolation of the active principle. J. Antibiot. 28: 721-726.

Vlahos, C.J., Matter, W.F., Hui, K.Y., and Brown, R.F. 1994. A specific inhibitor of phosphatidylinositol 3-kinase, 2-(4morpholinyl)-8-phenyl-4H-1-benzopyran-4-one (LY294002). $J$. Biol. Chem. 2169: 5241-5248.

von Manteuffel, S.R., Gingras, A.-C., Ming, X.F., Sonenberg, N., and Thomas, G. 1996. 4E-BP1 phosphorylation is mediated by the FRAP-p70s6k pathway and is independent of mitogen-activated protein kinase. Proc. Natl. Acad. Sci. 93: 4076-4080.

von Manteuffel, S.R., Dennis, P.B., Pullen, N., Gingras, A.-C., Sonenberg, N., and Thomas, G. 1997. The insulin-induced signalling pathway leading to $\mathrm{S} 6$ and initiation factor $4 \mathrm{E}$ binding protein 1 phosphorylation bifurcates at a rapamycinsensitive point immediately upstream of p70s6k. Mol. Cell. Biol. 17: 5426-5436.

Wang, X., Campbell, L.E., Miller, C.M., and Proud, C.G. 1998. Amino acid availability regulates p70 66 kinase and multiple translation factors. Biochem. J. 334: 261-267.

Weinkove, D., Neufeld, T.P., Twardzik, T., Waterfield, M.D., and Leevers, S.J. 1999. Regulation of imaginal disc cell size, cell number and organ size by Drosophila class I(A) phosphoinositide 3-kinase and its adaptor. Curr. Biol. 9: 10191029.
West, M.J., Stoneley, M., and Willis, A.E. 1998. Translational induction of the c-myc oncogene via activation of the FRAP/ mTOR signalling pathway. Oncogene 17: 769-780.

Weyrich, A.S., Dixon, D.A., Pabla, R., Elstad, M.R., McIntyre, T.M., Prescott, S.M., and Zimmerman, G.A. 1998. Signaldependent translation of a regulatory protein, Bcl-3, in activated human platelets. Proc. Natl. Acad. Sci. 95: 5556-5561.

Whitman, M., Kaplan, D.R., Schaffhausen, B., Cantley, L., and Roberts, T.M. 1985. Association of phosphatidylinositol kinase activity with polyoma middle-T competent for transformation. Nature 315: 239-242.

Wickens, M., Goodwin, E.B., Kimble, J., Strickland, S., and Hentze, M.W. 2000. Translational control of developmental decisions. In Translational control of gene expression (ed. N. Sonenberg, J.W.B. Hershey, and M.B. Mathews), pp. 295-370. Cold Spring Harbor Laboratory Press, Cold Spring Harbor, New York.

Wiederrecht, G., Brizuela, L., Elliston, K., Sigal, N.H., and Siekierka, J.J. 1991. FKB1 encodes a nonessential FK 506-binding protein in Saccharomyces cerevisiae and contains regions suggesting homology to the cyclophilins. Proc. Natl. Acad. Sci. 88: 1029-1033.

Wu, X., Senechal, K., Neshat, M.S., Whang, Y.E., and Sawyers, C.L. 1998. The PTEN/MMAC1 tumor suppressor phosphatase functions as a negative regulator of the phosphoinositide 3-kinase/Akt pathway. Proc. Natl. Acad. Sci. 95: 1558715591.

Xu, G., Kwon, G., Marshall, C.A., Lin, T.A., Lawrence, Jr., J.C., and McDaniel, M.L. 1998a. Branched-chain amino acids are essential in the regulation of PHAS-I and p70 S6 kinase by pancreatic beta-cells. A possible role in protein translation and mitogenic signaling. J. Biol. Chem. 273: 28178-28184.

Xu, G., Marshall, C.A., Lin, T.A., Kwon, G., Munivenkatappa, R.B., Hill, J.R., Lawrence, Jr., J.C., and McDaniel, M.L. 1998b. Insulin mediates glucose-stimulated phosphorylation of PHAS-I by pancreatic beta cells. An insulin-receptor mechanism for autoregulation of protein synthesis by translation. J. Biol. Chem. 273: 4485-4491.

Yang, D.-Q. and Kastan, M.B. 2000. Participation of ATM in insulin signaling through phosphorylation of eIF-4E-binding protein 1. Nat. Cell Biol. 2: 893-898.

Zhang, H., Stallock, J.P., Ng, J.C., Reinhard, C., and Neufeld, T.P. 2000. Regulation of cellular growth by the Drosophila target of rapamycin dTOR. Genes \& Dev. 14: 2712-2724.

Zheng, X.F., Florentino, D., Chen, J., Crabtree, G.R., and Schreiber, S.L. 1995. TOR kinase domains are required for two distinct functions, only one of which is inhibited by rapamycin. Cell 82: 121-130.

Zong, Q., Schummer, M., Hood, L., and Morris, D.R. 1999. Messenger RNA translation state: The second dimension of high-throughput expression screening. Proc. Natl. Acad. Sci. 96: $10632-10636$. 


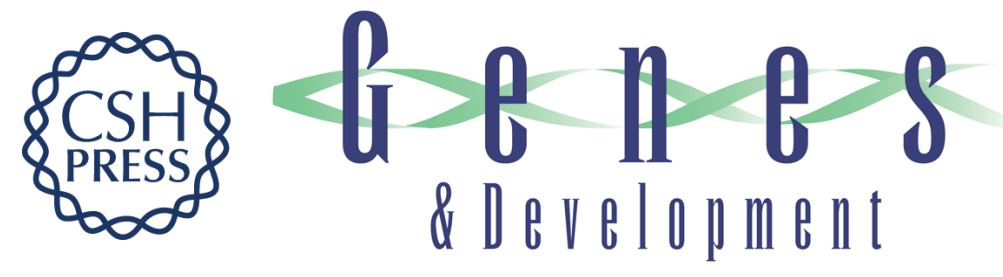

\section{Regulation of translation initiation by FRAP/mTOR}

Anne-Claude Gingras, Brian Raught and Nahum Sonenberg

Genes Dev. 2001, 15:

Access the most recent version at doi:10.1101/gad.887201

References This article cites 210 articles, 125 of which can be accessed free at: http://genesdev.cshlp.org/content/15/7/807.full.html\#ref-list-1

License

Email Alerting Receive free email alerts when new articles cite this article - sign up in the box at the top Service right corner of the article or click here.

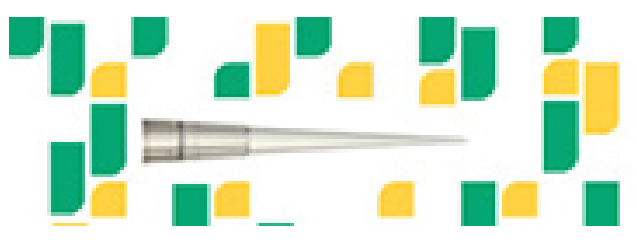

Focused on your science. 